Florida International University FIU Digital Commons

\title{
A descriptive correlation of medication and dietary compliance beliefs with functional limitations in heart failure patients
}

Dorothy B. Diener

Florida International University

DOI: $10.25148 /$ etd.FI14062289

Follow this and additional works at: https://digitalcommons.fiu.edu/etd

Part of the Nursing Commons

\section{Recommended Citation}

Diener, Dorothy B., "A descriptive correlation of medication and dietary compliance beliefs with functional limitations in heart failure patients" (2000). FIU Electronic Theses and Dissertations. 2817.

https://digitalcommons.fiu.edu/etd/2817 
FLORIDA INTERNATIONAL UNIVERSITY

Miami, Florida

\begin{abstract}
A DESCRIPTIVE CORRELATION OF
MEDICATION AND DIETARY COMPLIANCE BELIEFS WITH

FUNCTIONAL LIMITATIONS IN HEART FAILURE PATIENTS
\end{abstract}

A thesis submitted in partial fulfillment of the

requirements for the degree of

MASTER OF SCIENCE

in

NURSING

by

Dorothy B. Diener 
To: Dean Ronald Berkman

College of Health Sciences

This thesis, written by Dorothy B. Diener, and entitled A Descriptive Correlation of Medication and Dietary Compliance Beliefs with Functional Limitations in Heart Failure Patients, having been approved in respect to style and intellectual content, is referred to you for judgment.

We have read this thesis and recommend that it be approved.

Tomas Madayag

Maxine Hamilton

Luz Porter, Major Professor

Date of Defense: April 5, 2000

The thesis of Dorothy B. Diener is approved.

Dean Ronald Berkman College of Health Sciences

Dean Richard L. Campbell Division of Graduate Studies

Florida International University, 2000 


\section{DEDICATION}

I dedicate this thesis to Marc. Without his unwavering understanding and faith in me, gentle humor and unconditional love, the completion of this work would not have been possible. 


\section{ACKNOWLEDGMENTS}

I wish to thank the members of my committee for their patient assistance rendered so generously, without which, the successful completion of this thesis would have been impossible.

I wish to thank Dr. Tomas Madayag and Dr. Maxine Hamilton for their unfailing confidence and support in my pursuit of this project; their caring is only matched by their professionalism. A special thank you is due Dr. Luz Porter for sharing her time and great wisdom as well as her expert guidance. These three people stand as the best examples of mentors; their positive influence is an invaluable and cherished gift.

Thanks are due Dr. Friederman for her instruction on data organization and the use of SPSS. Her excellent lecture enabled me to complete statistical analysis of these research findings. I am also grateful to Dr. Susan Bennett of Indiana University for the privilege of using her scales to measure compliance beliefs and to all the heart failure patients who gave their time and effort in participation. Special acknowledgement is also due in recognition of the kind assistance and expertise of the Cardiac Care Center and CHF Clinic at Broward General Medical Center offered in support of this study.

For the loving support and continuous encouragement of my dear family, friends and colleagues, I remain, very grateful. 


\title{
ABSTRACT OF THE THESIS
}

\section{A DESCRIPTIVE CORRELATION OF MEDICATION AND DIETARY COMPLIANCE BELIEFS WITH FUNCTIONAL LIMITATIONS IN HEART}

\section{FAILURE PATIENTS}

by

\author{
Dorothy B. Diener
}

Florida International University, 2000

$$
\text { Miami, Florida }
$$

Professor Luz Porter, Major Professor

In order to determine the existence of a relationship between heart failure patients' compliance beliefs and functional limitations, using a convenience sample of 61 adults attending a specialized outpatient heart failure clinic, responses to scale items measuring perceptions of benefits and barriers to compliance with medication and diet were collected and functional limitations were self ranked by symptoms experienced with activities of daily living. A positive correlation (Spearman's rho $=0.345, p=.007$, level of significance $=.01$ ) between patients' functional limitations and perceived benefits to medication compliance scores was found while a negative correlation (Spearman's rho $=-0.310$, $p=.015$, level of significance $=.05$ ) between functional limitations and perceived barriers to medication compliance scores was found. Patients' functional limitations correlated with neither benefits nor barriers to diet compliance scores. It is recommended that nurses assess and utilize heart failure patients' functional limitations to individualize interventions aimed at influencing compliance beliefs. 


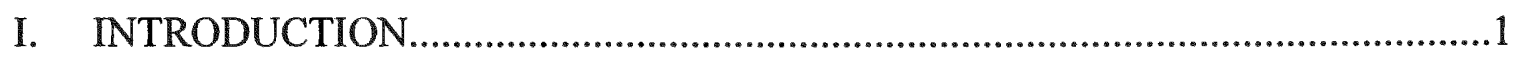

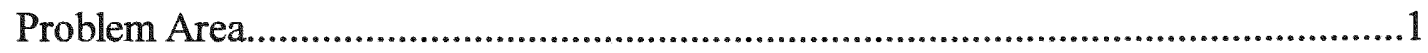

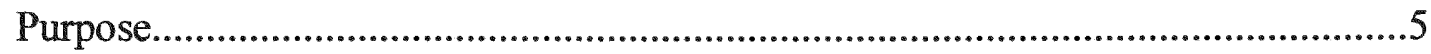

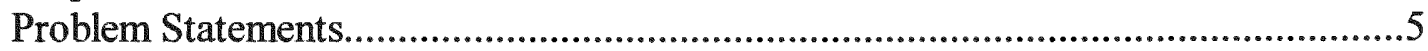

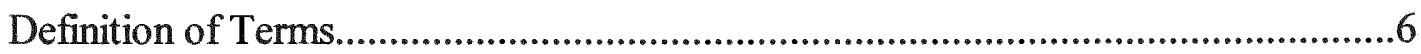

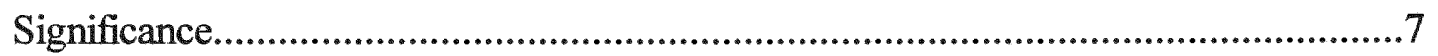

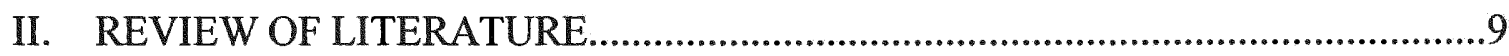

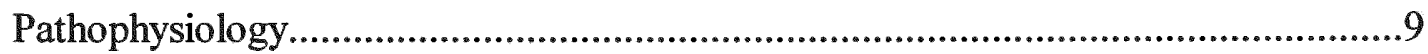

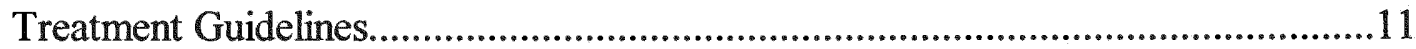

Compliance with Therapeutic Regimen...............................................................15

Compliance and Rehospitalization......................................................................22

New Management Strategies...........................................................................25

Conceptual/Theoretical Framework.....................................................................28

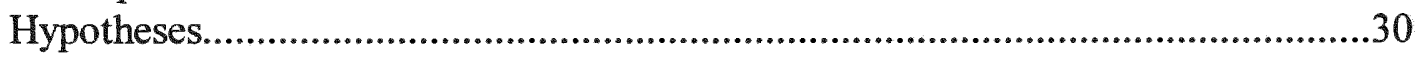

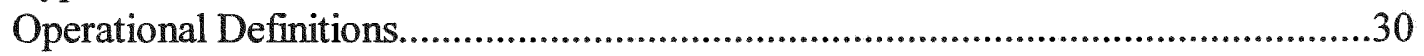

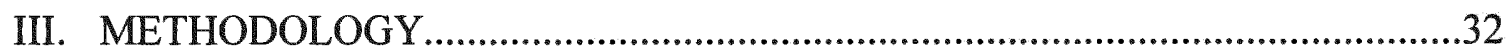

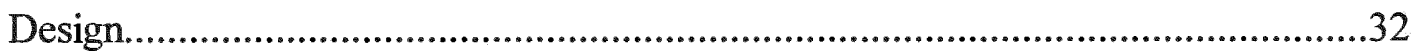

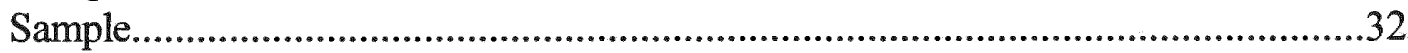

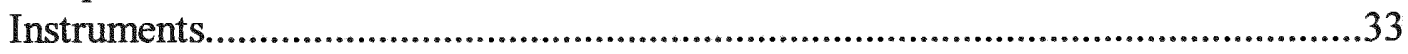

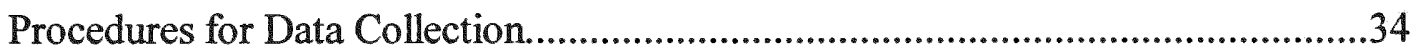

Method of Data Analysis.....................................................................................35

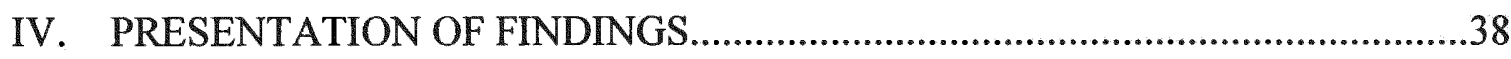

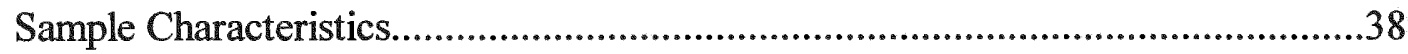

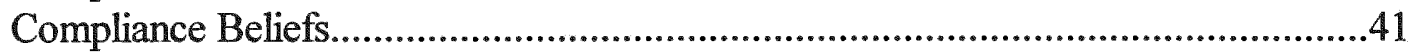

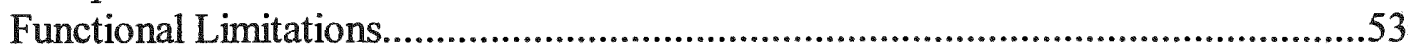

Relationships between Compliance Beliefs and Functional Limitations....................55

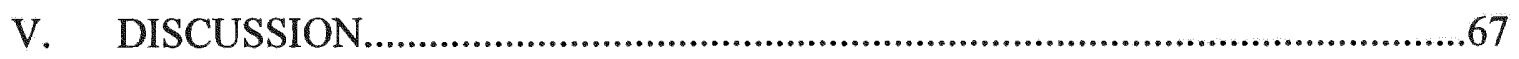

Discussion and Comparisons................................................................................67

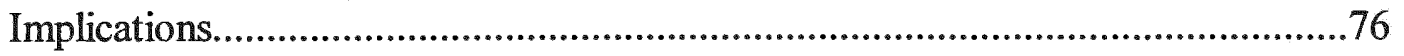

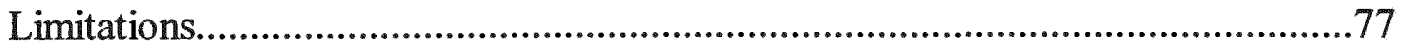

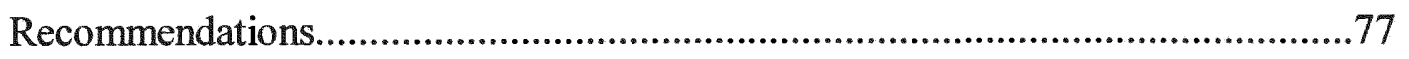

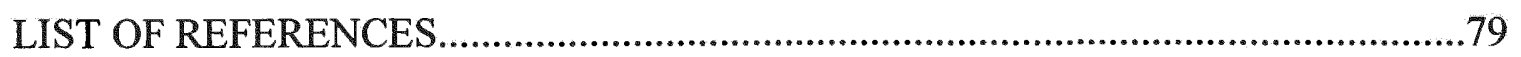

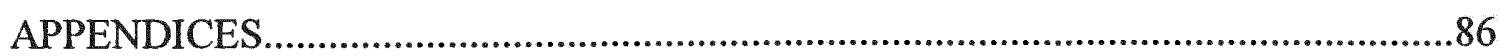




\section{LIST OF TABLES}

1. Distribution of Sample Characteristics by Study: Gender, Race, Symptom Stage and Age Comparison.

2. Perceived Benefits to Medication Compliance Ranked by Sample Percentage Indicating Agreement.

3. Frequency Distribution of Sample According to Perceived Benefits of Medication Compliance

4. Perceived Barriers to Medication Compliance Ranked by Sample Percentage Indicating Agreement.

5. Frequency Distribution of Sample by Perceived Barriers to Medication Compliance.

6. Perceived Benefits to Dietary Compliance Ranked by Sample Percentage Indicating Agreement.

7. Frequency Distribution of Sample by Perceived Benefits of Dietary Compliance.

8. Perceived Barriers to Dietary Compliance Ranked by Sample Percentage Indicating Agreement.

9. Frequency Distribution of Sample by Perceived Barriers to Dietary compliance.

10. Descriptive Data for Study Comparison: Compliance Benefit and Barrier Mean Scores and Ranges.

11. Correlations between Functional Limitations (Symptom Stage) and Therapeutic regimen Compliance Beliefs (Subscale Mean Scores).

12. Correlations between Functional Limitations (Symptom Stage) and Perceived Benefits of Medication Compliance.

13. Correlations between Perceived Benefits of Medication Compliance.

14. Correlations between Functional Limitations (Symptom Stage) and Perceived Barriers to Medication Compliance. 
15. Correlations between Perceived Barriers to Medication Compliance.....................62

16. Correlations between Functional Limitations (Symptom Stage) and Perceived Benefits to Dietary Compliance.

17. Correlations between Perceived Benefits of Dietary Compliance..........................64

18. Correlations between Functional Limitations (Symptom Stage) and Perceived Barriers to Dietary Compliance.

19. Correlations between Perceived Barriers to Dietary Compliance...........................66 


\section{CHAPTER I \\ INTRODUCTION}

\section{PROBLEM AREA}

The broad aim of this study is to shed light on the complex, human behavioral response set of compliance and what may influence it. Compliance with treatment regimen in chronic illness, particularly heart failure, is my locus of concern.

I became interested in the concept of compliance with frequent clinical exposure to examples of noncompliance when working as a geriatric medical/surgical nurse. I found the consequent physical, psychosocial and financial costs associated with noncompliance to be exorbitant.

My current work in cardiac and cardiovascular intensive care frequently brings the chronically ill heart failure client into my sphere of influence. This patient presents a wealth of opportunities for health promotion. Ultimately, patient educational interventions aimed at improving self management of chronic illness may improve patient quality of life.

In 1994, the Agency for Health Care Policy and Research Clinical Practice Guideline (Konstam et al., 1994) stated that almost one million Americans were hospitalized annually with heart failure and suffered a five year mortality rate in the range of 50 percent. In 1990, 10 billion dollars in total treatment costs were assessed for heart failure (Konstam et al., 1994). The American College of Cardiology and the American Heart Association (ACC/AHA) Task Force reported 4,700,000 Americans diagnosed with congestive heart failure and a six year mortality rate approaching 80 percent in men and 65 percent in women (ACC/AHA Task Force, 1995). Both publications warned of increasing 
incidence and mortality rate as the United States population ages, an alarming prediction (ACC/AHA Task Force, 1995; Konstam et al., 1994).

The Centers for Disease Control and Prevention (CDCP) explained increases in CHF (congestive heart failure) death rates and hospitalization rates among older age groups from 1980-1990 with "increasing average age of the U.S. population and the longer survival of persons with hypertension or symptomatic cardiac diseases who subsequently develop CHF at an older age" (1994, p.79). Calls to action include the need for more population-based data to assess trends in incidence, survival, management practices and application of treatment strategies for heart failure (Goldberg, 1999; Senni et al., 1999).

New practice guidelines for the prevention, diagnosis and treatment of heart failure have been developed by expert consensus (Advisory Council to Improve Outcomes Nationwide in Heart Failure/ACTION HF, 1999). The primary focus of these guidelines is the rapidly changing pharmacologic management of chronic heart failure secondary to left ventricular systolic dysfunction which accounts for 80 to $90 \%$ of heart failure patients.

Today, heart failure is the only major cardiovascular disease of increasing incidence and prevalence. It is now reported (ACTION HF, 1999) that 4.8 million in the United States are afflicted with 400,000 to 700,00 new cases of heart failure occuring annually accounting for approximately 1.5 to $2 \%$ of the US population with heart failure. Approximately 250,000 direct and indirect deaths due to heart failure occur annually representing a six fold increase in the past forty years of number of deaths due to heart failure as a primary or secondary cause (ACTION HF, 1999). Twenty to forty billion dollars in direct expenditures for heart failure in this country annually have been estimated 
with annual hospitalization costs estimated at $\$ 8$ to $\$ 15$ billion. Three and a half million hospitalizations for heart failure occur annually with this clinical syndrome being a leading cause of hospitalization among people over 65 . Discouragingly, approximately $33 \%$ of patients hospitalized for heart failure are readmitted within 90 days (ACTION HF, 1999).

This latest treatment guideline (ACTION HF, 1999) defines goals of treatment addressing these startling statistics: improve symptoms, improve quality of life, decrease disease progression, decrease risk of death and decrease need for hospitalization.

Assuming accepted standard therapeutic regimens are efficacious in the management of this chronic disease, understanding the influences on patient compliance with them may ultimately serve to lessen the public health burden ascribed to this diagnosis. Health care practitioners diagnosing heart failure and prescribing treatment are consequently important to the exploration of patient compliance. If positive patient outcomes like decreased rates of rehospitalization and the ability to evaluate individual treatment efficacy are practice goals, then patient compliance with prescribed treatment and what may promote, impede or relate to that compliance are important practice issues.

A review of the literature related to heart failure patients reveals their clinically significant rehospitalization rates ( Bennett et al., 1998; Ghali, Kadakia, Cooper \& Ferlinz, 1988; Haldeman, Croft, Giles, Rashidee, 1999; Happ, Naylor \& Roe-Prior, 1997; Krumholz et al., 2000; Krumholz et al., 1997; Michalsen, Konig \& Thimme, 1998; Opasich et al., 1996; Rich et al., 1995; Shah, Der, Ruggerio, Heidenrich \& Massie, 1998; Struthers, Anderson, Donnan, \& MacDonald, 2000; Vinson, Rich, Sperry, Shah, \& McNamara, 1990 ). Precipitant and preventable contributory factors for 
readmission include lack of adherence to prescribed medication and/or dietary regimens as supported by studies formerly referenced and that of West et al. (1997). Chin and Goldman (1997) found self reported patient compliance did not correlate with early hospital readmission or death.

A large body of knowledge has been accumulated regarding compliance as a phenomenon including its predictors, determinants, measurements and correlates with Sackett and Haynes' classical work "Compliance with Therapeutic Regimens" remaining a definitive reference (1976).

A sociobehavioral model for the further study of compliance with therapeutic regimens was derived by M.H. Becker with modification of the Health Belief Model. This Health Belief Model grew from origins in Kurt Lewin's Social Science Field Theory and from the work of social scientists: Hochbaum, Kegeles, Leventhal and Rosenstock in the 1950's and 1960's (Rosenstock, 1974).

The Health Belief Model (HBM) argues that an individual's perceptions of personal susceptibility to illness, severity of illness consequences (presence of or past experience with symptoms), the health action's benefits ( effective reduction or prevention of susceptibility/severity), and barriers related to undertaking the health actions (physical, psychological or financial costs) will influence whether or not an individual will undertake a recommended health action (Becker, 1974). Based on this Model, scales were developed to measure heart failure patients' beliefs (perceived benefits and barriers ) regarding medication and dietary compliance (Bennett, Milgrom, Champion \& Huster, 1997). 


\section{PURPOSE}

The purpose of this study was to measure beliefs about medication and dietary compliance in heart failure patients in a South Florida health care program using the instrument developed by Bennett et al. (1997). These investigators suggested that heart failure patients' compliance beliefs may differ according to their classification level of disease. Bennett et al. stated that "beliefs about compliance might be different for patients with varying classes of heart failure because of the differences in heart failure related symptoms" (1997, p.278). In order to determine the existence of a relationship between compliance beliefs and heart failure class, participating patients were asked to report functional limitations indicating presence of or experience with symptoms (Becker, 1974; Bennett et al., 1997).

\section{PROBLEM STATEMENT}

To what extent do therapeutic regimen compliance beliefs relate to functional limitations in heart failure patients enrolled in a specialized, outpatient heart failure clinic?

1. What are the beliefs about medication compliance among heart failure patients?

1.1 What are perceived benefits to medication compliance?

1.2 What are perceived barriers to medication compliance?

2. What are the beliefs about dietary compliance among heart failure patients?

2.1 What are perceived benefits to dietary compliance?

2.2 What are perceived barriers to dietary compliance?

3. What are the functional limitations among heart failure patients?

4. What is the relationship between function limitations and: 
4.1a. Beliefs about Medication Compliance/perceived benefits

4.1b. Beliefs about Medication Compliance/perceived barriers

4. 2a. Beliefs about Dietary Compliance/perceived benefits

4. 2b. Beliefs about Dietary Compliance/perceived barriers

\section{DEFINITION OF TERMS}

\section{HEART FAILURE}

Heart failure is a clinical syndrome or condition characterized by (1) signs and symptoms of intravascular and interstitial volume overload, including shortness of breath, rales, edema, or (2) manifestations of inadequate tissue perfusion, such as fatigue or poor exercise tolerance.These signs and symptoms result when the heart is unable to generate a cardiac output sufficient to meet the body's demands (Konstam et al., 1994, p.11).

BELIEFS. Beliefs refer to the individual heart failure patient's perceptions about compliance with medication and dietary regimen. These perceptions are measurable and tend to stratify along two axes; benefits of and barriers to compliance with therapeutic regimen (Bennett et al., 1997).

COMPLIANCE. "the extent to which the patient's behavior coincides with the clinical prescription, regardless of how the latter was generated" (Sackett \& Haynes, 1976, p.2).

BENEFITS. Perceived benefits are "belief in the efficacy or value of a behavior in reducing the threat" posed by illness ( Becker, Maiman, Kirscht, Haefner \& Drachman, 1975, p. 349). 
BARRIERS. Perceived barriers are "estimates of physical, psychological, financial or other costs involved in the proposed action" (Becker, Maiman, Kirscht, Haefner \& Drachman, 1975, p.349).

FUNCTIONAL LIMITATIONS. The Agency for Health Care Policy and Research Clinical Practice Guideline (Konstam et al., 1994) utilizes the New York Heart Association (NYHA) four tier classification system (I-IV) to define increasing states of functional limitation in cardiac disease patients:

NYHA levels (of functional limitation) can be described as follows:

I--Cardiac disease without resulting limitations of physical activity

II--Slight limitation of physical activity--comfortable at rest, but ordinary physical activity results in fatigue, palpitation, dyspnea, or anginal pain

III--Marked limitation in physical activity--comfortable at rest, but less than ordinary physical activity causes fatigue, palpitation, dyspnea, or anginal pain IV--Inability to carry on any physical activity without discomfort or symptoms at rest.

Although criticized for a lack of reliability, this system is still widely used (p.43).

\section{SIGNIFICANCE}

A highly symptomatic heart failure patient reporting marked functional limitation may perceive greater susceptibility to illness or severity of illness consequences than the asymptomatic, functionally capable heart failure patient. A more symptomatic patient may perceive their therapeutic regimen differently. If self reported functional limitations designating heart failure class may be related to therapeutic regimen compliance beliefs, 
both may influence whether or not an individual will undertake a recommended health action (Becker, 1974).

Assessing and utilizing heart failure patient's beliefs about compliance and factors that relate to those beliefs may allow practitioners to better individualize educational interventions that ultimately increase compliance with medication and dietary regimen treating this incurable disease.

The significance of this study stems from its attempt to both describe and explore what may potentially influence compliance with treatment in the practical management of a costly chronic illness. Increased compliance with therapeutic regimen may maximize the individual's health potential by both promoting better health and preventing acute decompensation and rehospitalization in the heart failure patient. 


\section{CHAPTER II \\ REVIEW OF THE LITERATURE}

A literature review was undertaken to elucidate heart failure and compliance with medication and diet as factors in patient decompensation. The pathophysiology of this chronic disease, current treatment guidelines and new management strategies promoting therapeutic regimen compliance were also reviewed.

\section{PATHOPHYSIOLOGY}

McKee, Castelli, McNamara and Kannel (1971) performed retrospective analyses of Framingham study subjects; a classic, epidemiologic study, "coded for the presence of congestive heart failure during the preceding 16 years" (p.1441). As evidenced by 75 percent of studied cases, congestive heart failure development was found most frequently preceded by hypertension and demonstrated high mortality rates with probability of death five years following onset at 62 percent for males and 42 percent for females (McKee et al., 1971). In this cohort of 5,192 persons initially free from disease, 3.5 percent of males and 2.1 percent of females developed overt myocardial insufficiency within 16 years; then noted as "far from trivial" (McKee et al., 1971, p.1444). The magnitude of this health problem is formally realized here. The burden of this disease entity was then and is now only expected to increase as the United States geriatric population increases (ACC/AHA Task Force, 1995; Konstam et al., 1994; McKee et al., 1971).

The 1980's saw the investigation of the roles of several neuroendocrine systems in relationship to the hemodynamics of heart failure denoting a marked change in study focus from the previous half century (Cody et al., 1989; Francis et al., 1990; Levine et al., 
1982). The pathophysiology of heart failure had been described primarily in hemodynamic terms alone secondary to ventricles unable to pump the demanded blood supply to the periphery (Packer, 1992).

A delicate balance of hemodynamic and neurohormonal mechanisms serve to compensate the failing heart. However, "long-term activation of endogenous positive, inotropic and stress-reducing mechanisms leads to a diminuition of their favourable physiological effects" (Packer, 1992, p.89).

It has been found that even before overt, symptomatic heart failure, in the earliest stages of left ventricular dysfunction, activation of vasoconstriction and vasodilation mechanisms occur (ACC/AHA Task Force, 1995; Francis et al., 1990; Hsu, 1996). As the failing heart decompensates in an effort to support systemic perfusion and perfusion pressures, sustained neurohormonal activation results in peripheral vasoconstriction, and sodium and water retention. Counter regulatory vasodilatory mechanisms in the kidney and periphery are lost. This counter regulatory loss further compounds the loss of compensatory myocardial mechanisms decreasing subsequent ability to maintain cardiac output (Packer, 1992).

There is biochemical evidence of sympathetic activation in heart failure with deleterious effects as follows: beta receptor down regulation, myocardial remodeling, cardiotoxic changes, associated ventricular arrhythmias and immunologic alterations with response deficits induced by increased sympathetic activity. Mortality has been shown to correlate to measurements of circulating catecholamines in heart failure patients (Pepper \& Lee, 1999). 
In short, the pathophysiology of heart failure is complex with compensatory biochemical pathways. Without support, these mechanisms are eventually overwhelmed and decompensation is inevitable. Thereby a low sodium diet and cardiovascular medications are integral to the long term management of this chronic illness. Therapeutic regimen comprised of medication and low sodium diet serve to complement and support the body's compensatory efforts aiding the failing heart (ACTION HF, 1999; ACC/AHA Task Force, 1995; Hsu, 1996).

\section{TREATMENT GUIDELINES}

It is the evolving pathophysiology of heart failure that shapes its medical management. Hsu (1996) purports the following treatment principles to guide heart failure management: "eliminate precipitating factors of heart failure, decrease myocardial workload, increase myocardial contractility, decrease sodium and water retention and facilitate ventricular relaxation" (p.96). Cohn (1996) emphasizes targeting those "therapeutically modifiable mechanisms" of heart failure progression in the fight to prolong life, namely:

vasoconstriction due to neural, hormonal, or endothelial factors that increase the impedance load on the left ventricle; activation of the sympathetic nervous system and the renin-angiotensin system, which can stimulate the growth of tissue in the myocardium and the peripheral vasculature; neurohormonal or tissue induced mechanisms that have direct toxic effects on myocytes; progressive enlargement or remodeling of the left ventricle; local or circulatory influences that induce ventricular arrhythmia; and thromboembolic events (p.494).

Practice standards for medical management of heart failure today incorporate these principles. 
The clinical practice guideline "Heart failure: Evaluation and care of patients with left ventricular systolic dysfunction" (Konstam et al., 1994), the ACC/AHA Task Force report "Guidelines for the evaluation and management of heart failure" (1995) and the "Consensus recommendations for the management of chronic heart failure" (ACTION HF, 1999) comprise the currently accepted evaluation and treatment standards for heart failure in the United States. These guidelines are research based and derived from expert consensus opinion serving to steer clinical practice decisions for the sound medical management of heart failure.

Regarding diet as a management intervention in heart failure, these expert references cite sodium restriction as integral. Konstam et al. (1994) advise dietary sodium intake restriction from two grams to a strict three grams, daily. ACC/AHA Task Force (1995) cites sodium restriction as a critical treatment strategy. ACTION HF (1999) recommends as a general treatment measure, moderate daily sodium intake (less than or equal to 3 grams daily) with daily weight monitoring to effectively utilize lower, safer diuretic doses. Other, secondary, authoritative sources concur that dietary sodium excess is a precipitant factor in heart failure and should be restricted (Aronow, 1997; Dracup, Baker, Dunbar et al., 1994; Hsu, 1996; Karon, 1995).

Regarding pharmacologic management, angiotensin converting enzyme (ACE) inhibitors are sole treatment for an indefinite time period if: well tolerated and patient is only symptomatic with fatigue or mild exertional dyspnea or is asymptomatic with significant left ventricular systolic dysfunction (an ejection fraction less than 35-40 percent) (ACTION HF, 1999; ACC/AHA Task Force, 1995; Konstam et al., 1994; The 
SOLVD investigators, 1991). ACE inhibitors conserve potassium and relieve symptoms by reducing aldosterone secretion (Cohn, 1996).

Hydralazine and isosorbide dinitrate is an acceptable alternative if $\mathrm{ACE}$ inhibitors are contraindicated or poorly tolerated (ACC/AHA Task Force, 1995; Konstam et al., 1994). In some cases of heart failure with abnormal left ventricular ejection fraction, hydralazine and isosorbide dinitrate as vasodilator therapy, may be used in combination with $\mathrm{ACE}$ inhibitors (Aronow, 1997; Cohn et al., 1991).

If the patient remains symptomatic with $\mathrm{ACE}$ inhibitors and a low sodium diet, or for any overt signs or symptoms of volume overload, diuretics are added to the regimen and continued (even when edema free) with dosage and type adjustments (ACC/AHA Task Force, 1995; Konstam et al., 1994). Diuretics are a "therapeutic cornerstone" and are the "only reliable means of controlling fluid retention of heart failure" ( ACTION HF, 1999, p.12A). Diuretics are important as a class for their ability to alter efficacy and toxicity of nearly all other drug therapies used to treat heart failure; a necessary though insufficient therapy (ACTION HF,1999).

Since this literature review was initiated, beta blockers are now recommended for use in NYHA Class II or III heart failure secondary to left ventricular systolic dysfunction with diuretics and $\mathrm{ACE}$ inhibitors. These drugs may reduce risk of disease progression even if no symptom decrease is realized (ACTION HF, 1999).

Digoxin is recommended to improve clinical status with heart failure secondary to left ventricular systolic dysfunction in concert with diuretics, ACE inhibitors and beta 
blockade therapy (ACTION HF, 1999) and in patients with rapid ventricular response rates secondary to atrial fibrillation (ACC/AHA Task Force, 1995; Konstam et al., 1994; The Digitalis Investigation Group, 1997).

Anticoagulants are recommended for patients with atrial fibrillation or a history of pulmonary or systemic embolism. Mild to moderate exercise like walking or recreational bike riding is encouraged to prevent/reverse physical deconditioning. Overexertion is to be avoided (ACTION HF, 1999; ACC/AHA Task Force, 1995; Konstam et al., 1994).

On first literature review, the use of carvedilol (an alpha 1 and beta 2 adrenergic blocker) and losartan, (an angiotensin II receptor antagonist) were both noteworthy for conferring some symptomatic relief without adverse mortality outcomes (Packer et al., 1 1996; Pitt et al., 1997). Now, as mentioned, beta blockade is incorporated into recommended treatment guidelines and no persuasive evidence has demonstrated angiotensin II receptor antagonists equivalency or superiority to ACE inhibitors in the treatment of heart failure. Large scale trials of drugs in both categories are in progress (ACTION HF, 1999).

Investigational research for effective medications to reduce morbidity and mortality in heart failure patients remains ongoing. The fact also remains, that short of cardiac transplantation, there is no cure for heart failure. Appropriate prescription of efficacious treatment to informed, compliant heart failure patients engenders their maximum health potential. "Current therapy for heart failure can maintain function, improve quality of life and prolong survival" notes Dracup, Baker, Dunbar et al., (1994).

The best pharmacologic and dietary treatment regimens are only efficacious if heart 
failure patients comply with them. Konstam et al., (1994) cite noncompliance as a major cause of morbidity and hospitilization in heart failure. Their clinical practice guideline emphasizes practitioner awareness of noncompliance and its causes as integral to the successful management of heart failure patients (1994). "Although it is clear that noncompliance is a major problem in caring for patients with heart failure, it is less clear what should be done to improve this situation" (Konstam et al., 1994, p.147). "Noncompliance with diet and medication can rapidly and profoundly affect the clinical status of patients..." ( ACTION HF, 1999, p.11A).

\section{COMPLIANCE WITH THERAPEUTIC REGIMEN}

Patients' beliefs concerning their susceptibility to disease and the benefits and barriers to therapy are conceptual dimensions of the Health Belief Model (HBM). These potentially related dimensions are also empirically measurable variables and are central to the assessment of the chronically ill heart failure patient. Maiman, Becker, Kirscht, Haefner and Drachman (1977) applied the HBM to chronic illness behavior performing multivariate testing to its major dimensions, developing reliable scales for dimension measurements and explicating relationships among beliefs. This study provided a rich, descriptive assessment of HBM dimensions and relationships to long term therapeutic regimen (diet modification). Individuals' compliance behaviors correlated with measured health beliefs (Maiman et al., 1977).

Jenkins (1979) considered problems of health related behavior as symptoms and advocated making a behavioral diagnosis. As always, a diagnostic process is begun with careful assessment. The HBM concepts including perceived severity/susceptibility, benefits 
and barriers were advocated for use as a guide to explore the full nature and history of noncompliance. "If the barier to health promoting behavior is a lack of appropriate information or an incorrect belief system, the health worker's intervention will focus on successful communication" (p.13).

Given, Given, Gallin and Condon (1983) constructed scales to measure chronically ill diabetic patients' beliefs about their disease and therapy using HBM concepts as a framework also.

These scales represent a useful tool for transferring greater responsibility to patients for the management of their diabetes. This process should begin with an assessment of patients' beliefs about such issues as their ability to control the effects of diabetes, the barriers to, as well as support for carrying out therapy, and their beliefs regarding that therapy (p.140).

Given et al. (1983) asserted psychosocial assessment as a necessary first step to constructing behavioral interventions for increasing patient involvement in the management of their chronic illness.

In 1985, Becker reviewed the state of the art for research regarding patient adherence to prescribed therapies. He asserted "that efforts to enhance patient regimen adherence should attend to the attitude and belief dimensions of the HBM in addition to other likely influences on health-related behavior" (p.544).

Redeker (1988) focused on a review of the literature regarding compliance issues specific to chronic illness and health beliefs. Further development and testing of valid and reliable tools for nursing assessment in these areas is called for. This work and further study of interaction among HBM variables was asserted as essential and preliminary to the testing of interventions designed to support compliance behaviors. 
In 1979, R.B. Haynes wrote in introduction of the work "Compliance in Health Care" that "it is no longer possible to execute an exhaustive review of the scientific literature on compliance" (p.6). Apparently, since the dawn of medicine, compliance with therapeutic regimen has been a part of the human condition. Haynes (1979) references Hippocrates who warns fellow physicians to remain mindful of patients frequently lying when queried regarding medication compliance!

The literature on compliance with therapeutic regimen is vast. Its most consistent elements remain its inherent complexity and controversy as a human behavioral response. Seminal to this research work and indivisible from the study of all compliance issues is Sackett and Haynes” (1976) “Compliance with Therapeutic Regimen”. This edited work was the outgrowth of a symposium held at McMaster's University in 1974. The authors reviewed the existing literature to that time with strict scientific rigor and their many findings remain often-quoted as central tenets to compliance studies even today.

In an attempt to assess the magnitude of compliance and noncompliance, many inconsistencies were revealed secondary to the mechanics of study like design, sampling and how compliance was operationally defined. A distinction important to the hypotheses of this work emerged. Symptomatic patients showed higher rates of compliance with their therapeutic regimens, regardless of how that compliance was operationalized (Sackett and Haynes, 1976).

Many factors were studied in relationship to compliance including patient demographics and sociobehavioral features, disease features, features of the therapeutic regimen and the interaction between patient and therapist. Demographics were noted to 
more generally affect access to health care rather than compliance with therapy.

Psychiatric diagnoses were found to have a negative association with compliance behavior. Reduced compliance was associated with three regimen features: (a) greater complexity, (b) greater patient behavioral changes, and (c) longer continuance over time. Continuity of care with regular providers and reduced waiting times for pharmacy, appointments and referrals are positively associated with compliance. A high degree of care provider supervision with the regimen is also positively associated with compliance (Sackett and Haynes, 1976).

Patient dissatisfaction with care provider interaction is associated with noncompliance. Previous or present noncompliance with other regimens is also associated to non compliance with a particular recommendation. Family instability and innapropriate health beliefs were also associated with noncompliance (Sackett and Haynes, 1976).

The Health Belief Model which will be fully explored as the conceptual/theoretical framework for this study, was shown by Sackett and Haynes (1976) to have predictive value with both prospective and retrospective compliance studies. Prospective studies showed weaker relationships with the model suggesting changes in compliance behavior may precede not follow changes in patients' health beliefs.

Other important conceptual issues such as strategies to improve compliance were reviewed and criticized in this classic work. Methodologic issues important to compliance research including compliance measures and their correlation with treatment goals were also explored having been identified as impediments to the development of new knowledge (Sackett and Haynes, 1976). 
Romm, Hulka and Mayo (1976) undertook a study of 122 congestive heart failure patients to correlate health care process measures with patient outcome measures. The patient group with less symptomatology initially, had a process measure in the doctor-patient relationship realm positively related to outcome. Overall, the best predictor of final health status was initial health status and not those measured aspects of the process of care.

Hulka, Cassel, Kupper and Burdette (1976) selected a stratified random sample of 46 physicians and their respective heart failure patients enrolled for study when visiting their participant physician. Characteristics of medication regimen, doctor-patient communication affecting patient medication taking behavior and physician awareness of medication taking behaviors were evaluated. Errors of omission, comission, scheduling misconception and scheduling noncompliance were defined. Low levels of all error types were found with good communication of instructions and information from physician to heart failure patient. Greater errors of omission and commission were associated with greater number of drugs prescribed in the doctor-patient pair. Greater errors of commission and scheduling misconceptions were associated with more complex schedules for administration of medications.

Methods for the evaluation of patient compliance with medication regimen were often the subject of evaluation. In 1979, Fletcher, Pappius and Harper evaluated the measurement of patient compliance with prescribed digoxin by interview, pill count and serum digoxin concentration (SDC). "Interview was more feasible, easier,and more timely than either pill count or measurement of SDC." (p.637). Compliance measurement by 
interview correlated with SDC's in these patients. Cummings, Kirscht, Becker and Levin (1989) compared blood chemistries, health professionals' ratings and patients' self reports for assessing patient compliance with medication regimen. It was concluded that a variety of measures providing a multifaceted assessment of adherence is the best assurance to accurately gauge a patient's compliance with therapeutic regimen. The Center for Health Promotion and Education of the Centers for Disease Control provided new information on strategies to promote patient self managment of chronic disease (1982). Ethnicity and number of daily prescribed pills were the only significant predictors from the multivariate analysis of noncompliance in an evaluation of 249 male veterans (Gravely \& Oseasohn, 1991).

DiMatteo et al. (1993) explored the role of the health care provider in promotion of therapeutic regimen compliance among diabetic, hypertensive and heart disease patients. Medication and diet adherence was found to decline significantly in this group over the life of this 2 year longitudinal study. Eleven of 132 comparisons showed statistically significant positive effects of adherence on health outcomes in the Medical Outcomes Study (MOS), another notable longitudinal study in 1993. Hays et al. in this 4 year observational study of 2,125 adult chronic disease patients (including some with heart failure) concluded that the relationship between health outcomes and adherence with therapeutic regimens was much more complex than previously assumed.

A retrospective follow up study of 7,247 patients newly prescribed digoxin (as verified with the complete prescription claims file of the New Jersey Medicaid program) revealed only 10 percent of the study population filled enough prescriptions to have this 
daily heart failure medication available for the entire follow up year (Monane, Bohn, Gurwitz, Glynn \& Avorn, 1994).

Cameron (1996) identified social and psychological factors thought to influence compliance. Development of a therapeutic relationship and monitoring of compliance behavior were advocated here.

\section{COMPLIANCE AND REHOSPITALIZATION}

In a definitive prospective study of 101 urban heart failure patients, Ghali, Kadakia, Cooper and Ferlinz (1988) evaluated the frequency and relative importance of precipitant factors leading to hospital admission for decompensated heart failure. Noncompliance was the term used by investigators describing those subjects who stopped taking all their medications, took medication only intermittently and/or who demonstrated dietary indiscretion and recent sodium excess prior to worsening symptoms. Noncompliance was assessed by subjective patient self report of the aforementioned conditions. Twenty two percent of patients studied were noncompliant with diet alone while $6 \%$ of patients were found noncompliant with medications alone. Noncompliance with both diet and medications was found in $37 \%$ of patients studied. Noncompliance with entire medical regimen or any of its parts was the most commonly identified precipitant factor found in $64 \%$ of this study cohort (Ghali et al., 1988).

Of 140 prospectively evaluated hospitalized patients with documented heart failure surviving an index admission, $47 \%$ (66) were readmitted within 90 days (Vinson, Rich, Sperry, Shah, \& McNamara, 1990). Readmissions were evaluated by diagnosis, reason and preventability. Dietary or medication noncompliance deemed avoidable by improved 
patient education or medication review were thereby categorized as remediable factors contributing to potentially preventable readmissions. Medication noncompliance contributed to $15 \%$ of readmissions and diet noncompliance contributed to $18 \%$ of readmissions respectively in this 90 day evaluation (Vinson et al., 1990).

Opasich et al. (1996) prospectively evaluated 304 heart failure patients referred to a specialized unit for care in Italy. "Decompensation was defined as a worsening of NYHA class associated with the need for an increase in medical treatment (at minimum, intravenous diuretics). Only nonfatal decompensations were considered" (p.354). Three hundred twenty eight decompensations were identified by direct observation, case history and clinical records. Lack of adherence to prescribed medical and nonmedical regimens was found in $15 \%$ of decompensations. Therapeutic strategies incorporating preventive measures for these potentially precipitant factors were called for by investigators.

Krumholz et al. (1997) conducted an observational study in Connecticut using Medicare administrative files and found that 7,596 patients or $44 \%$ of 17,448 survivors of index hospitalization for heart failure were readmitted within 6 months of that index admission . Clarification of readmission determinants was called for by the investigators. Happ, Naylor and Roe-Prior (1997) undertook a notable qualitative evaluation of advanced practice nurse (APN) logs, physician's notes, medical record summaries, admission interviews and study questionnairres from the files of 16 elderly heart failure patients to determine factors contributing to rehospitalization. "Medication adherence particularly diuretic dosing, was the most commonly identified and most recalcitrant problem documented by APN's"' (p.80). 
Dietary nonadherence themes were expressed as unwillingness or inability to change diet habits and as dietary indiscretions. Another theme found here and categorized as a poor health behavior, was a history of nonadherence to treatment regimen prevalent among the rehospitalized portion of the cohort.

Chin and Goldman (1997) prospectively evaluated 257 hospitalized heart failure patients, discharged alive from index admission, for readmission or death. Approximately one third of this cohort was readmitted within 60 days of discharge. Patient compliance was not correlated with readmission nor death. Investigators questioned compliance scales for sufficient sensitivity. Most notably, investigators were unable to identify a truly low risk group within this patient cohort and asked the question : Is it possible to describe a clinically significant low rate of readmission among heart failure patients?

Michalsen, Konig \& Thimme (1998) prospectively recruited and evaluated during a one year period, a consecutive sample of 179 acutely decompensated, previously diagnosed, heart failure patients on hospital readmission. Noncompliance with diet or drug treatment was most commonly identified as a causative factor accounting for $41.9 \%$ of these cardiac decompensation cases.

Bennett et al. (1998) found compliance with therapeutic regimen difficult to determine secondary to retrospective record review in a study of 1,992 hospital admissions for heart failure. Excessive sodium retention was found to be a leading factor associated with patient decompensation. Investigators suggested implementation of behavioral interventions to improve compliance with medication regimen and low sodium 
diet as a means to reduce this decompensation risk.

Krumholz et al. (2000) retrospectively evaluated 2,176 patients 65 years of age and older with a primary diagnosis of heart failure on hospital discharge and found 4 of 32 factors examined to be associated with rehospitalization: prior hospital admission within the year, prior heart failure diagnosis, diabetes mellitus diagnosis and an elevated serum creatinine level $(>2.5 \mathrm{mg} / \mathrm{dl})$. Admittedly, due to retrospective nature of the study design, as in the Bennett et al. study (1998), investigators cite only the ability to evaluate clinical factors versus psychosocial factors related to rehospitalization risk. As in the Chin and Goldman study (1997), investigators were unable to identify a group of heart failure patients at very low risk for readmission suggesting that any elderly patient surviving admission for heart failure should be considered at risk for readmission.

Outcome measures were for all emergency hospital admissions and for cardiac emergency admissions with an effort to examine if treatment nonadherence was greater in socially deprived versus other socioeconomic groups, in a study of 478 chronic heart failure patients (Struthers, Anderson, Donnan and MacDonald, 2000). All patients had had previous hospitalization for heart failure, had had myocardial infarction and were on diuretic therapy. Investigators found that social deprivation increased rehospitalization chance of the chronic heart failure patient independent of disease severity as judged by dose of diuretic prescribed. Diuretic adherence was operationalized as the percentage of time during study when patients had diuretics available at home. As per Struthers et al.(2000), diuretic nonadherence could not be dismissed as a potential contributor to rehospitalization nor could dietary nonadherence secondary to the cross sectional design 
of the study.

\section{NEW MANAGEMENT STRATEGIES}

Pearson and Peters (1997) describe the known treatment gap between guidelines for risk reduction and disease management in coronary artery disease and heart failure patients and the actual care these patients are receiving. Inpatient/hospital programs, specialist/generalist communication, ambulatory care and patient compliance are all potential barriers playing a part to limit optimal care of these patients thereby creating the “treatment gap".

In 1992, Buschnell conducted a small descriptive study and found that almost all participants could not correctly define heart failure and less than half could correctly identify their medicines. Hagenhoff, Feutz, Conn, Sagehorn and Moranville-Hunziker (1994) cited the lack of published information regarding learning needs of the heart failure patient and adapted a tool originally developed for myocardial infarction patients to measure perceptions about learning needs. Agreement was found between hospitalized heart failure patients and their nurses that medication information was the most important and realistic patient education content to be learned.

Nurse directed, multidisciplinary intervention was found to increase quality of life and reduce hospital use and associated medical costs for elderly heart failure patients in a prospective, randomized trial of intervention versus conventional care by Rich et al. (1995). "A multidisciplinary treatment strategy is associated with improved medication compliance during the first 30 days following hospital discharge in elderly patients with CHF" (Rich, Gray, Beckham, Wittenberg \& Luther, 1996, p.270). Assignment to 
intervention group was the strongest independent predictor of medication compliance with rates significantly higher by pill count assessment for those of the 156 participants randomized to the study intervention.

Hanumanthu, Butler, Chomsky, Davis and Wilson (1997) found that of 134 patients followed, $94 \%$ were hospitalized during the year before referral versus $44 \%$ hospitalized during the year after referral intervention managed by heart failure specialists in a dedicated program (versus management by physicians not specializing in heart failure). Fewer hospitalizations and greater exercise tolerance were found after specialized management.

1997 was also notable for the study of Fonarow et al. Two hundred fourteen NYHA Class III and IV heart failure patients awaiting transplantation experienced significantly decreased hospital readdmission rates and improved functional status during the 6 month period following comprehensive management including medical therapy and intensive education than in the previous 6 month period with no specialized management.

Another comprehensive management system for heart failure was evaluated in 1997 called MULTIFIT by West et al. In a small (51 participants) nonrandomized study, this home based, nurse mediated and physician supervised program was evaluated. MULTIFIT implemented consensus guidelines for medication and dietary therapy and close monitoring by frequent telephone contact. Statistically significant improvements were found including (a) decreased daily sodium intake (b) increased daily medication doses (c) functional status and exercise capacity improvements (d) decreased emergency room visits and hospitalization rates as compared to the previous year before program enrollment. 
Program efficacy may be more conclusively demonstrated with a larger randomized trial.

Laing and Behrendt (1998) described an interactive home health care management program for heart failure patients without providing any standardized outcomes such as comparative hospitalization rates pre and post program enrollment with which to objectify its efficacy versus other interventional programs.

A 27 participant pilot study was also completed in 1998 by Shah, Der, Ruggerio, Heidenreich and Massie testing an interactive home monitoring program of heart failure patients. It was suggested here that close telephone monitoring of recently discharged and ambulatory outpatients could prevent rehospitalizations among these patients. In a follow up study to this pilot, Heidenreich, Ruggerio and Massie (1999) suggest that a multidisciplinary program of patient monitoring, education and physician notification implemented in community practice settings can contribute to decreased hospitalizations and medical claims in a group of elderly heart failure patients.

In summary, the body of accumulated literature regarding compliance behavior is vast. Compliance with therapeutic regimen in heart failure is necessitated both by its pathophysiology and lack of cure. There are efficacious medication and dietary regimens for heart failure management. Rehospitalization rates for this chronic illness are clinically and statistically significant. Medication and dietary regimen noncompliance has been implicated as precipitant in the rehospitalization of heart failure patients. Specialized management, including strategies to support and promote compliance with therapeutic regimen, has been found effective in the fight to decrease rehospitalization rates in this vulnerable patient population. 


\section{CONCEPTUAL/THEORETICAL FRAMEWORK}

The Health Belief Model (HBM) emerged from the Public Health Service (early 1950 's) orientation toward disease prevention and the problem solving orientation of social psychologists influenced by Lewinian theory. These scientists were committed to theory building. Rosenstock (1974) described those earliest Model characteristics translated from Lewin's valence abstractions. In order for disease avoidance action to be taken, the individual must perceive susceptibility or subjective risks of contracting a condition and perceive seriousness or that the condition would create important life difficulties. These perceptions were thought to provide a force leading to preventive health action. The particular course of action would be charted by the individual's beliefs. The "net" beliefs or the perceived benefits of taking action minus the perceived barriers of taking action would determine the likelihood of taking recommended preventive health action. "The combined levels of susceptibility and severity provided the energy or force to act and the perception of benefits (less barriers) provided a preferential path of action" (Rosenstock, 1974, p.332). Denoted as a modifying factor and less well studied was the variable described as cues to action (an internal or external instigating event). Other modifying factors were demographic, sociopsychological and structural variables (Rosenstock, 1974).

On the basis of literature reviewed for patient acceptance of recommended health actions, sick role behavior was incorporated into the fabric of the HBM to better predict likelihood of compliance with prescribed regimens (Becker, 1974; Becker \& Maiman, 
1975). In the sick role, diagnosis of illness has already occurred. The concept of perceived susceptibility was maintained as patients belief in the diagnosis or its recurrence was found positively associated with compliance behavior. The presence of (or past experience with) symptoms affected perceived severity (Becker, 1974).

Becker (1974) stated:

The presence of physical symptoms probably exerts an elevating or "realistic" affect on perceived severity, motivating the patient to follow the physician's instructions as long as the organic indications of illness persist (or to avoid their recurrence). Such behavior would increase the probability of the researcher's obtaining positive correlations between perceived severity and compliance, at least for the early stages of treatment (p.413).

Perceived benefits and barriers were maintained as variables associated with likelihood of prescribed regimen compliance in sick role behavior (Becker, 1974; Becker \& Maiman, 1975). Becker and Maiman (1975) outline the "need for research that would attempt to enhance compliance by modifying the sociobehavioral or other elements proposed in the Model “ (p.21).

Strategies derived from the Health Belief Model suggest methods for accomplishing patient compliance and other behavior change related to treatment regimens versus reliance on information sharing or use of professional status as the primary care provider influencing patient behavior (Elder, Ayala \& Harris, 1999). Elder et al. recommend discovering patients' preconceptions regarding health behavior changes as they relate to the prevention of illness by assessing patient perceptions of benefit and barrier to engaging in the health behavior and assessing perceptions of susceptibility and severity of outcome. These perceptions individualize the health message to be communicated. Discussing how 
to overcome perceived barriers to health behavior and incorporating perceived benefits as reinforcers of the recommended behavior are strategies derived from the Health Belief Model which may mediate patient compliance as health behavior change (Elder et al., 1999).

\section{HYPOTHESES}

Two simple, directional hypotheses may be derived from the problem statement : To what extent do therapeutic regimen compliance beliefs relate to functional limitations in heart failure patients enrolled in a specialized, outpatient heart failure clinic?

1. There is a positive relationship between patients' functional limitations (designated by symptom stage/ NYHA Class level) and perceptions of benefit from medication and dietary compliance (scores on Beliefs about Medication Compliance and Beliefs about Dietary Compliance Benefits subscales).

2. There is a negative relationship between patients' functional limitations (designated by symptom stage/NYHA Class level) and perceptions of barriers to medication and dietary compliance (scores on Beliefs about Medication Compliance and Beliefs about Dietary Compliance Barriers subscales).

\section{OPERATIONAL DEFINITIONS}

An operational definition is "the definition of a concept or variable in terms of the operations or procedures by which it is to be measured" (Polit and Hungler, 1991, p.650). New York Heart Association class I-IV designations were used to define participants' functional limitations. The definitive treatment guidelines which provide practice standards for heart failure management today utilize NYHA class designations to rank severity of 
functional limitation. These guidelines also support patient self reports as assessment of functional incapacity. (ACTION HF, 1999; ACC/AHA Task Force, 1995; Konstam et al., 1994). As previously noted, this classification system has been criticized. These designations were clarified by the translation of medical jargon into corresponding lay terminology. Content validity was supported by expert panel review. Physical activities were more fully described to further simplify and delineate class distinctions (ACC/AHA Task Force,1995). These clarifications better serve study participants to self describe their level of functional limitation.

Heart failure patients' beliefs about compliance with medication and dietary regimen were measured . Participants used a five point scale (from 1=strongly disagree, to $5=$ strongly agree) to answer questions designed to measure patient perceptions of benefits and barriers to compliance with a therapeutic regimen. The Beliefs about Medication Compliance Scale and Beliefs about Dietary Compliance Scale each contain items to assess perceived benefits and barriers. Participant scores therefore reflected four subscales: benefits to medication compliance, barriers to medication compliance, benefits to dietary compliance and barriers to dietary compliance (Bennett et al., 1997). 


\section{CHAPTER III \\ METHODOLOGY}

\section{DESIGN}

This is a descriptive correlational study designed to assess compliance beliefs among select heart failure patients by survey. The subsequent determination of whether or not a relationship exists between compliance beliefs and functional limitations in heart failure patients stems from an influencing factor described as a potential limitation in the Beliefs about Compliance instrument development study of Bennet et al. (1997).

Nonexperimental research was undertaken appropriately here to describe various characteristics of a select population and to test a theoretical proposition. Designed as a descriptive correlational study, there is no intention to elucidate cause and effect relations between the described variables here. A recognized weakness is the potential selection bias inherent in studying preexisting versus randomly formed groups of heart failure patients. (Polit and Hungler, 1991).

\section{SAMPLE}

Bennett et al. (1997) recruited 61, alert, oriented, English speaking patients with a medical diagnosis of heart failure from a hospital's specialized outpatient clinic to participate in the development of an instrument designed to measure beliefs about compliance with medication and diet. I, the principal investigator, obtained a convenience sample utilizing the study inclusion criteria of Bennett et al. (1997) by recruiting 61 alert, oriented English speaking, male and female patients, 18 years of age and older from a 
South Florida outpatient heart failure clinic to participate in the utilization of the aforementioned authors' tool to assess compliance beliefs. In order to recruit the sample, the principal investigator was present at the clinic site during regular hours of operation, two to three days per week for a period of 10 weeks. Most clinic patients' appointments were scheduled in advance, some were added on and others were seen during regular hours without appointments as "walk-ins". Patients seen by special appointment outside of routine clinic hours were not recruited. Participants were recruited by the principal investigator in the clinic waiting area as they arrived. Patients were excluded from potential participation if they did not speak English. Patients were also excluded if they were not on diuretic therapy as the majority of scale items measuring beliefs about medication compliance refer to taking water pills. Three patients were excluded as nonEnglish speakers over the duration of data collection ( 2 Hispanic and 1 Haitian, speaking only Spanish and Creole, respectively).

\section{INSTRUMENTS}

\section{a. Demographics}

Participants indicated their race, sex, age and New York Heart Association (NYHA) class level I-IV by operational definition to indicate functional limitations. This demographic information was obtained in order to assess generalizability of findings, ascertain study limitations and make meaningful comparisons. The content validity of NYHA class designations operationalized to allow patient self reporting of functional limitations was supported by expert panel review.

b. Compliance Beliefs 
Two scales, Beliefs about Medication Compliance and Beliefs about Dietary Compliance, comprised the tool utilized to assess heart failure patients' beliefs about therapeutic regimen compliance (Bennett et al., 1997).

Participants used a 5 point Likert scale (1=strongly disagree, $2=$ disagree, $3=$ undecided, $4=$ agree and 5=strongly agree) to respond to 24 items designed to measure perceptions of benefits and barriers to compliance with medication and diet. As psychosocial scales, the Beliefs about Medication Compliance Scale (BMCS) and the Beliefs about Dietary Compliance Scale (BDCS) are appropriately evaluated for reliability in terms of their internal consistency (Munro, 1997). "Internal consistency reliabilities of the perceived benefits and barriers subscales of the BMCS and BDCS were computed using Cronbach's alpha statistic" with reported values ranging from 0.68 to 0.91 (Bennett et al., 1997, p.277). A content validity index of 0.81 was determined and found acceptable. Construct validity of both the BMCS and BDCS was supported by factor analysis yielding two subscales for each scale; perceived benefits and barriers (Bennett et al., 1997).

\section{PROCEDURES FOR DATA COLLECTION}

Research protocol approval was granted by Florida International University and following full review, IRB approval was granted by the participating agency. Informed consent was obtained from all participants by the principal investigator. Clinic patients were provided a copy of the consent document explaining study purpose, nature of participation, participant selection, potential risks and benefits, confidentiality pledge and study contact persons. Having been so informed and after indicating their consent, clinic 
patients responded to questionnaires. The principal investigator administered each questionnaire at the outpatient heart failure clinic site by reading all items as they appeared and recording participants responses as indicated by those heart failure patients. The questionnnaire packets were comprised of the Beliefs about Medication Compliance Scale, the Beliefs about Dietary Compliance Scale and a page for participants to describe their demographic characteristics and functional limitations. A five to ten week time frame was estimated and required to obtain 61 study participants. All completed questionnaires were secured by the principal investigator and will remain stored in a locked cabinet for a minimum of three years in the investigator's home.

All study participants were enrolled in a specialized multidisciplinary heart failure clinic limiting a potential weakness in design. Bennett et al. (1997) denoted a study limitation with having $40 \%$ of their participants recruited from private practice settings and the remaining 61 participants, $60 \%$ of the sample, recruited from a specialized heart failure clinic. Bennett et al. noted that clinic attendees, by nature of their enrollment, may be considered to have greater therapeutic regimen knowledge and compliance (1997). In exploring the relationship between compliance beliefs and functional limitations, a sample of all clinic attendees may be considered more homogeneous for regimen knowledge and compliance with regimen versus the dichotomous group recruited for the original instrument development study of Bennett et al.

\section{METHOD OF DATA ANALYSIS}

Study participants were asked to identify their age in years, their race and their level of functional limitation. Each participant chose the best description of their own 
experience with symptoms. These descriptions of functional limitation, in increasing severity, were provided in writing, read by the principal investigator and corresponded to the appropriate New York Heart Association Class level of heart disease. Mean age, standard deviation and age range in years were calculated. Number and percentage of total participants were determined by race and New York Heart Association class as did Bennett et al. (1997).

Participants completed both the Beliefs about Medication Compliance and Beliefs about Dietary Compliance Scales. To recapitulate, individual item scores ranged from one to five points. Higher scores indicated increased perception of compliance belief (benefit or barrier); the participant's increasing agreement with the benefit or barrier item. Each scale item was coded as a benefit or barrier to compliance as per coding instructions provided by Dr. Bennett. Scores or participant responses to each benefit and barrier item were analyzed to determine their frequency distribution across the sample. Total item agreement by participants is reflected in the combination of positive responses (agree and strongly agree). Negative responses (strongly disagree and disagree) are combined in reported findings to reflect total item disagreement by participants.

Benefit and barrier item scores were totaled to obtain four subscale scores per participant: Benefits of medication compliance, barriers to medication compliance, benefits of dietary compliance and barriers to dietary compliance. Like subscale scores across the sample were totaled and their sum was divided by 61 (the number of participants) to obtain a mean score for each aforementioned subscale, respectively. The means, standard deviations and actual ranges of BMCS and BDCS scores were 
calculated for both the benefits and barriers subscales as did Bennett et al. (1997).

Compliance scale scores and NYHA class designations represent inherently ordinal data. Spearman's rho was determined designating the magnitude and direction of the relationship between these two variables (Polit and Hungler, 1991).

The problem statement central to this study formulated as the null hypothesis is: There is no relationship between compliance beliefs and functional limitations. The chosen correlation coefficient was further evaluated to accept or reject the null hypothesis. The critical value for rho, the correlation coefficient and test statistic, (level of significance $=0.05$ for a two-tailed test) was compared to the tabeled value. If the absolute value of the test statistic is greater than the tabled value (tabled value lies between 0.2500 and 0.2732 ) then the null hypothesis may be rejected with the conclusion that there is a significant relationship between beliefs about compliance and functional incapacity (Polit and Hungler, 1991).

Spearman's rho was calculated using SPSS For Windows to determine the extent of relationship between a participant's symptom stage (functional limitation) and their perceived benefits/barriers to therapeutic regimen compliance.

The benefits' subscale scores (benefits of medication and dietary compliance) were utilized to test hypothesis 1 while each of the barriers' subscale scores (barriers of medication and dietary compliance) generated per participant were utilized to test hypothesis 2 . Tests of relationship between individual compliance belief items (perceived benefits and barriers to compliance with medication and diet) and symptom stage (functional limitation) were also performed. 


\section{CHAPTER IV \\ PRESENTATION OF FINDINGS}

Presented here are the findings of the study conducted with a convenience sample of 61 adult heart failure patients. Data is presented to illuminate sample characteristics, research questions and hypotheses. The SPSS computer program was used to complete statistical analysis. Sample characteristics and findings of Bennett et al.'s 1997 instrument development study are also denoted here for the purpose of discussion and comparison in Chapter V.

\section{SAMPLE CHARACTERISTICS}

The sample $(\mathrm{N}=61)$ was comprised of 40 males $(65.6 \%)$ and 21 females $(34.4 \%)$. Data reflects the diversity of the urban outpatient community served in South Florida. Seven participants were Hispanic (11.5\%), 20 participants were White Non Hispanic (32.8\%), 27 participants were Black Non Hispanic (44.3\%), 2 participants were Asian (3.3\%) and 5 participants (8.2\%) identified their race as other with mixed racial origins in the East and West Indies.

Sixteen participants (26.2\%) identified themselves as asymptomatic with no limitations to physical activity. This description operationally defines New York Heart Association (NYHA) Class I, the least severe stage of functional limitation. Thirty participants (49.2\%), the majority of my sample, identified themselves as symptomatic with moderate physical activity(walking 100 feet on level ground); NYHA Class II. Seven participants (11.5\%) identified themselves as symptomatic with minimal physical activity (dressing); NYHA Class III. Eight participants (13.1\%) identified themselves as symptomatic with any physical activity or at rest; NYHA Class IV, the most severe stage 
of functional limitation.

Seventy- five percent of my participants combined were identified as having NYHA Class I and Class II functional limitations versus $25 \%$ of my participants combined having more severe NYHA Class III and IV functional limitations.

Participants ranged in age from 30 to 79 years with a mean age of almost 53 (SD 10.3). The descriptive statistics denoting sample characteristics are displayed in Table 1. Relevant comparisons to the findings of Bennett displayed here will be drawn in Chapter V. 
Table 1 Distribution of sample characteristics by study: gender, race, symptom (sx) stage and age comparison

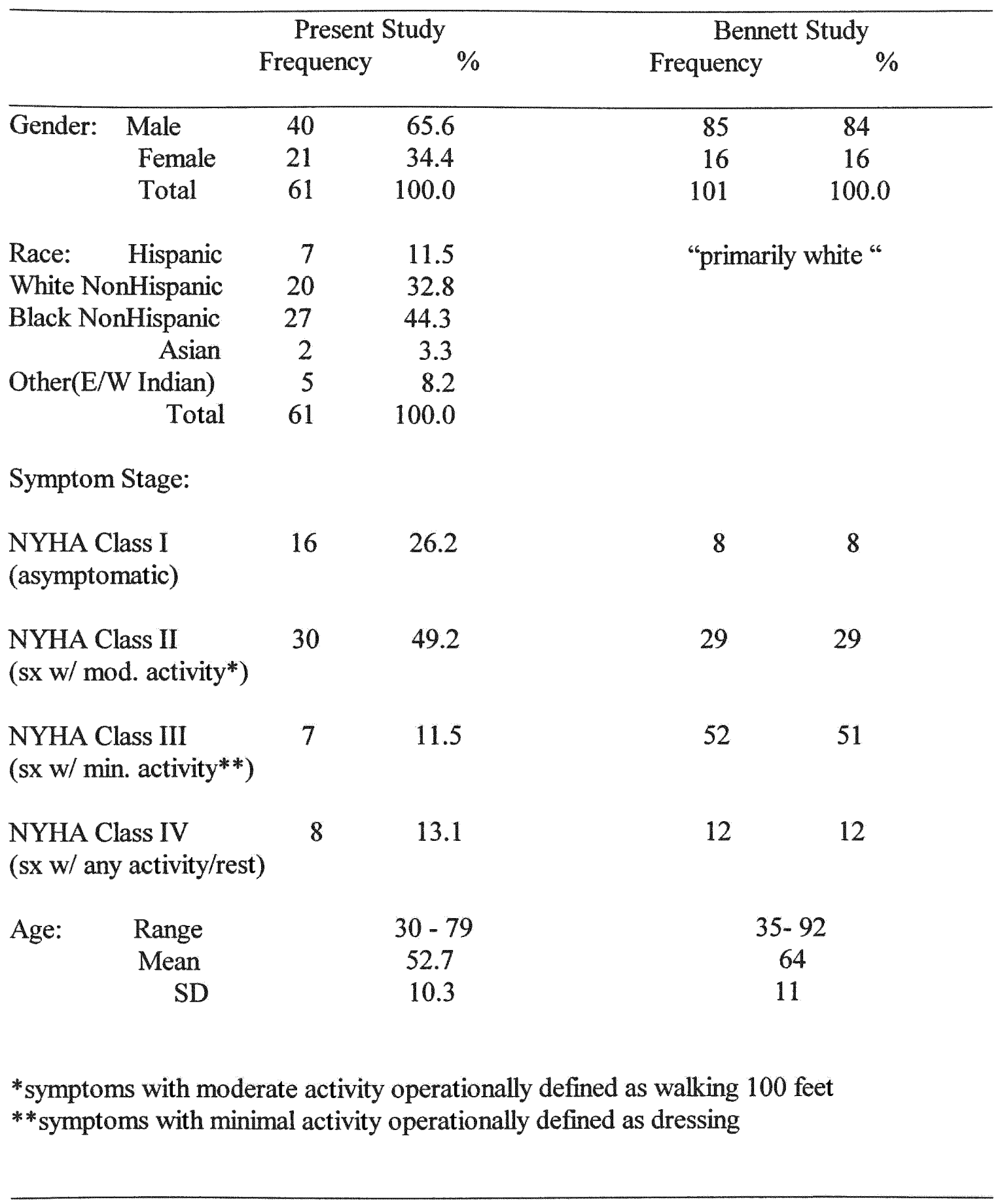




\section{COMPLIANCE BELIEFS}

Research question 1: What are the beliefs about medication compliance among heart failure patients in terms of perceived benefits and perceived barriers?

All 61 study participants completed the 12 item Beliefs about Medication Compliance Scale (BMCS) comprised of 5 perceived benefit and 7 perceived barrier items. Answers to this question are derived from responses of heart failure patients to preselected items pertaining primarily to taking daily diuretics as an integral part of their medication regimen.

\section{Perceived Benefits of Medication Compliance}

To recapitulate, the test items that measured heart failure patients' perceived benefits to medication compliance are as follows: "When I take my water pills, I do not worry as much about my heart disease", "If I take my water pills, I will lower my chance of being in the hospital", "Taking my water pills lessens my swelling", "Taking my water pills helps me breathe better" and "Taking my medicine improves my quality of life".

As depicted in Table 2, the greatest benefit of medication compliance as perceived by heart failure patients is an improved quality of life with $88.5 \%$ of the sample indicating agreement by positive responses to this item. The perceived benefits ranked second and third $(73.7 \%$ and $72.2 \%)$ regard compliance with diuretics providing decreased chance of hospitalization and decreased swelling, respectively. The final two benefits items also addressed compliance with diuretics and were ranked equally with only $45.9 \%$ of the sample indicating item agreement. Less than half of the sample perceived decreased worry about their heart disease and aid for better breathing from taking their water pills . 


\section{Table 2 Perceived benefits to medication compliance ranked by sample percentage indicating agreement}

1. Taking my medicine improves my quality of life (88.5\%)

2. If I take my water pills, I will lower my chance of being in the hospital $(73.7 \%)$

3. Taking my water pills lessens my swelling (72.2\%)

4. When I take my water pills, I do not worry as much about my heart disease $(45.9 \%)$

4. Taking my water pills helps me breathe better (45.9\%)

Table 3 depicts each benefit item and the frequency distribution of responses to that item. Only $11.5 \%$ of the sample were undecided or disagreed that compliance with medication improved their quality of life. Overall, benefits to diuretic compliance specifically, were less strongly perceived. While $26.2 \%$ were undecided or disagreed that taking water pills lessened the chance of hospitalization, $27.8 \%$ were undecided or disagreed that taking water pills lessened their swelling. A majority of the sample ( $54.1 \%$ ) were undecided or disagreed that when they took their water pills, they did not worry as much about their heart disease. The same percentage of participants $(54.1 \%)$ were undecided or disagreed that taking water pills helped them breathe better. 
Table 3 Frequency distribution of the sample according to perceived benefits of medication compliance $(\mathrm{N}=61)$

Benefit

Frequency

$\%$

Taking my medicine improves my quality of life

Agree /strongly agree

Undecided

54

4

Strongly disagree/disagree

Total
3

61
88.5

6.6

4.9

100.0

If I take my water pills, I will lower my chance

of being in the hospital

Agree/strongly agree

Undecided

Strongly disagree/disagree

Total

61

100.0

Taking my water pills lessens my swelling

Agree/strongly agree

Undecided

Strongly disagree/disagree

Total

When I take my water pills, I do not worry as much about my heart disease

Agree/Strongly agree

Undecided

Strongly disagree/disagree

Total

Taking my water pills helps me breathe better

Agree/strongly agree

Undecided

Strongly disagree/disagree

Total

61

100.0

\section{Perceived Barriers to Medication Compliance}

To recapitulate, the test items that measured heart failure patients' perceived barriers 
to medication compliance are the following: "Taking water pills is hard to remember", "Taking water pills is unpleasant", "I have to take too many water pills each day", "Taking water pills makes it hard for me to go away from home", "I forget to take my water pills", "Taking water pills makes me worry about my heart disease" and "Taking water pills wakes me up at night to go to the bathroom". As depicted in Table 4, the greatest barrier to medication compliance, specifically, taking diuretics, as perceived by heart failure patients is being made to wake up at night to go to the bathroom. Diffficulty going away from home ranked second as a perceived barrier to diuretic compliance among the sample. While $18.1 \%$ of the sample perceived taking water pills as unpleasant, $14.8 \%$ agreed to forgetting to take their water pills as a barrier to compliance. The three lowest ranking barriers to diuretic compliance as perceived by the sample were: "Taking water pills is hard to remember" with $9.8 \%$ indicating item agreement, "Taking water pills makes me worry about my heart disease" with $4.9 \%$ indicating item agreement and "I have to take too many water pills each day" with only $3.2 \%$ indicating item agreement.

\section{Table 4 Perceived barriers to medication compliance ranked by sample percentage indicating agreement.}

1. Taking water pills makes me wake up at night to go to the bathroom $(52.5 \%)$

2. Taking water pills makes it hard for me to go away from home $(24.6 \%)$

3. Taking water pills is unpleasant $(18.1 \%)$

4. I forget to take my water pills $(14.8 \%)$

5. Taking water pills is hard to remember $(9.8 \%)$

6. Taking water pills makes me worry about my heart disease $(4.9 \%)$

7. I have to take too many water pills each day (3.2\%)

Table 5 depicts each barrier item and the frequency of responses to that item. Overall, these items were not strongly perceived as barriers to compliance with diuretic therapy by 
the heart failure patients in this sample. While $52.5 \%$ of the sample perceived being made to wake up at night to go to the bathroom as a barrier to taking water pills, the remaining $47.5 \%$ therefore, were undecided or disagreed with the item. Almost $76 \%$ of these heart failure patients were undecided or disagreed that taking water pills made it hard for them to go away from home while almost $82 \%$ were undecided or disagreed that taking water pills is unpleasant. Slightly greater than $85 \%$ of the sample expressed indecision or disagreement with the item "I forget to take my water pills". Similarly, slightly greater than $90 \%$ were undecided or disagreed that "Taking water pills is hard to remember". Greater still were the percentages of the sample undecided or that disagreed with items "Taking water pills makes me worry about my heart disease" and "I have to take too many water pills each day". 


\section{Table 5 Frequency distribution of sample by perceived barriers to medication compliance $(\mathrm{N}=61)$}

Barriers

Frequency

$\%$

Taking water pills wakes me up at night to go to the bathroom

Agree/strongly agree

Undecided

Strongly disagree/disagree

Total

Taking water pills makes it hard for me to go away from home

Agree/strongly agree

Undecided

Strongly disagree/disagree

Total

Taking water pills is unpleasant

Agree/strongly agree

61

11

18.1

Undecided

Strongly disagree/disagree

70.5

Total

I forget to take my water pills

Agree/strongly agree

Undecided

Strongly disagree/disagree

Total

Taking water pills is hard to remember

Agree/strongly agree

Undecided

Strongly disagree/disagree

78.7

Total

100.0

Taking water pills makes me worry about my heart disease

Agree/strongly agree

Undecided

Strongly disagree/disagree

82.0

Total

100.0

I have to take too many water pills each day

Agree/strongly agree

Undecided

Strongly disagree/disagree 
Research question 2: What are beliefs about dietary compliance among heart failure patients in terms of perceived benefits and perceived barriers?

All 61 study participants completed the 12 item Beliefs about Dietary Compliance Scale (BDCS) comprised of 6 perceived benefits and 6 perceived barriers to compliance with recommended diet. Answers to this question are derived from responses of heart failure patients to preselected items pertaining to following a low sodium diet; a therapeutic intervention central to prudent heart failure management.

\section{Perceived Benefits of Dietary Compliance}

To recapitulate, the test items that measured heart failure patients' perceived benefits to dietary compliance are the following: "Eating a low salt diet will keep me healthy", "Eating a low salt diet will keep my heart healthy", "Eating a low salt diet will keep my swelling down", "Eating a low salt diet will keep fluid from building up in my body", "When I follow my low salt diet, I feel better" and "Eating a low salt diet will help me breathe easier". As depicted in Table 6 , the greatest benefit of dietary compliance as perceived by heart failure patients is keeping the heart healthy $(96.7 \%)$ followed closely the perception that eating a low salt diet will maintain general health (95.1\%). Also closely paired by rank as perceived benefits of eating a low salt diet are keeping fluid build up and swelling down ( 91.85 and $90.2 \%$, respectively). Eighty-two percent of the sample cites feeling better when low sodium compliant while only $59 \%$ perceive easier breathing as a benefit of eating a low salt diet. 


\section{Table 6 Perceived benefits to dietary compliance ranked by sample percentage indicating agreement}

1.Eating a low salt diet will keep my heart healthy $(96.7 \%)$

2.Eating a low salt diet will keep me healthy $(95.1 \%)$

3.Eating a low salt diet will keep fluid from building up in my body $(91.8 \%)$

4.Eating a low salt diet will keep my swelling down (90.2\%)

5. When I follow my low salt diet, I feel better (82\%)

6.Eating a low salt diet will help me breathe easier (59\%)

Table 7 depicts each benefit item and the frequency of responses to that item.

Overall, these items were strongly perceived as benefits to compliance with a low salt diet.

An exception across this sample of heart failure patients was the item "Eating a low salt diet will help me breathe easier". Forty one percent of participants were undecided or disagreed that diet compliance would ease their breathing. 
Table 7 Frequency distribution of sample by perceived benefits of dietary compliance $(\mathrm{N}=61)$

Benefits

Eating a low salt diet will keep my heart healthy

Agree/strongly agree

Undecided

Strongly disagree/disagree

Total

Eating a low salt diet will keep me healthy

Agree/strongly agree

Undecided

Strongly disagree/disagree

Total

Eating a low salt diet will keep fluid from building up in my body

Agree/strongly agree

Undecided

Strongly disagree/disagree

Total

Eating a low salt diet will keep my swelling down

Agree/strongly agree

Undecided

Strongly disagree/disagree

Total

When I follow my low salt diet, I feel better

Agree/strongly agree

Undecided

Strongly disagree/disagree

Total

Eating a low salt diet will help me breathe easier

Agree/strongly agree

Undecided

Strongly disagree/disagree

Total
Frequency

$\%$

59

96.7

2

3.3

0

61

0

100.0

58

95.1

2

3.3

1.6

61

100.0

56

91.8

4

6.6

1

1.6

61

100.0

55

90.2

3

4.9

3

4.9

61

100.0

50

82.0

4

6.6

7

11.4

61

100.0

36

59.0

19

31.2

6

9.8

61

100.0

\section{Perceived Barriers to Dietary Compliance}

To recapitulate, the test items that measured heart failure patients' perceived barriers 
to dietary compliance are as follows: "Salty food is not good for me", "I cannot go out to many places to eat because of the low salt diet", "Food does not taste good on the low salt diet", "Following a low salt diet costs too much money", "Following a low salt diet takes too much time" and "Following a low salt diet is too hard to understand". As depicted in Table 8, the greatest barrier to dietary compliance as perceived by heart failure patients is that salty food is not good for them. The remaining items were not strongly perceived barriers to dietary compliance across this sample. Less than half of the sample agreed that they could not go out to many places to eat because of dietary sodium restriction (49.2\%) and that food didn't tast good on the diet (45.9\%). Even fewer participants agreed that cost $(24.6 \%)$, complexity $(16.4 \%)$ and time (14.7\%) were diet compliance barriers.

\section{Table 8 Perceived barriers to dietary compliance ranked by sample percentage indicating agreement}

1. Salty food is not good for me (95.1\%)

2. I cannot go out to many places to eat because of the low salt diet $(49.2 \%)$

3. Food does not taste good on the low salt diet (45.9\%)

4. Following a low salt diet costs too much money $(24.6 \%)$

5. Following a low salt diet is too hard to understand (16.4\%)

6. Following a low salt diet takes too much time (14.7\%)

Table 9 depicts each barrier item and the frequency of responses to that item. Overall, these items were weakly perceived as barriers to dietary compliance with the exception of "Salty food is not good for me" to which greater than $95 \%$ of this sample indicated agreement. A majority of the sample was undecided or disagreed with the remaining barriers to dietary compliance: "I cannot go out to many places to eat because of the low 
salt diet" (50.8\%), "Food does not taste good on the low salt diet" (54.1\%), "Following a low salt diet costs too much money" (75.4\%), "Following a low salt diet is too hard to understand" (83.6\%), and "Following a low salt diet takes too much time " $(85.3 \%)$.

\section{Table 9 Frequency distribution of sample by perceived barriers to dietary compliance $(\mathrm{N}=61)$ \\ Barriers

Frequency $\quad \%$

Salty food not good for me

Agree/strongly agree

58

Undecided

Strongly disagree/disagree

Total

I cannot go out to many places to eat

because of the low salt diet

Agree/strongly agree

30

Undecided

Strongly disagree/disagree

Total

Food does not taste good on the low salt diet

Agree/strongly agree

Undecided

28

1

32

61

Total

Following a low salt diet costs too much money

Agree/strongly agree

Undecided

Strongly disagree/disagree

Total

\section{2}

61
61

49.2

8.2

42.6

100.0

45.9

1.6

52.5

100.0

24.6

0

75.4

100.0

16.4

1.6

82.0

100.0

Total

61

Following a low salt diet takes too much time

Agree/strongly agree

14.7

Undecided

Strongly disagree/disagree

50

3.3

Total

82.0

100.0 
compliance by perceived benefit/perceived barrier subscale mean score. Bennett's findings are denoted here for the purpose of later discussion and comparison. Higher scores again indicate increased participant perception of respective benefit or barrier to compliance. The possible total score range for each of the subscales, benefits to medication compliance and barriers to medication compliance, are 5 to 25 and 7 to 35 , respectively. . The mean score for participant perceived benefit to medication compliance was 18.57 (SD 2.56) with an actual range in benefit subscale scores of 14 to 25 . The mean score for participant perceived barriers to medication compliance was 16.75 (SD 3.33) with an actual range in barrier subscale scores of 11 to 28 .

The total, possible benefit or barrier subscale score range for the Beliefs about Dietary Compliance Scale was 6 to 30 , respectively. Actual scores for perceived benefits to dietary compliance ranged from 17 to 28 (mean=23.74, $\mathrm{SD}=2.29$ ) with scores for perceived barriers on this subscale ranging from 11 to 26 (mean=17.10, $\mathrm{SD}=3.23$ ). 
Table 10 Descriptive data for study comparison: Compliance benefit and barrier mean scores and ranges

\section{Present Study}

Scores

Beliefs/Medication

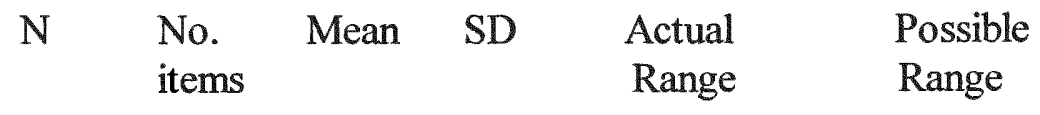

Compliance

$\begin{array}{lllllll}\text { Benefits Subscale } & 61 & 5 & 18.57 & 2.56 & 14-25 & 5-25 \\ \text { Barriers Subscale } & 61 & 7 & 16.75 & 3.33 & 11-28 & 7-35\end{array}$

Beliefs/Diet

Compliance

Benefits Subscale

Barriers Subscale

$\begin{array}{llllll}61 & 6 & 23.74 & 2.29 & 17-28 & 6-30 \\ 61 & 6 & 17.10 & 3.23 & 11-26 & 6-30\end{array}$

\section{Bennett Study}

Scores

$\mathrm{N}$ No. Mean SD items

Actual Possible

Range Range

Beliefs/Medication

Compliance

Benefits Subscale

985

19.84

3.84

10-25

$5-25$

Barriers Subscale

98

$13.07 \quad 3.44$

6-24

6-30

Beliefs/Diet

Compliance

Benefits Subscale

101

29.08

4.34

17-35

$7-35$

Barriers Subscale

101

12.70

4.00

$5-23$

$5-25$

\section{FUNCTIONAL LIMITATIONS}

Research question 3: What are the functional limitations among heart failure patients?

Functional limitations or symptom stages among heart failure patients are defined as increasingly severe from NYHA (New York Heart Association) Class I to Class IV. NYHA four tier classification system defining functional limitation is described below 
with the corresponding underlined description provided to study participants (in writing and as read by the principal investigator to the participant in administration of each survey) for self report of functional limitations.

NYHA Class I-Cardiac disease without resulting limitations of physical activity. I have been told I have heart failure but it does not limit my physical activity. NYHA Class II-Slight limitation of physical activity--comfortable at rest, but ordinary physical activity results in fatigue, palpitation, dyspnea, or anginal pain. I am comfortable at rest but walking 100 feet on level ground makes me feel: tired, short of breath, like my heart beats too fast, like my heart beats irregularly, pressurere in my chest, pain in my chest, tightness in my chest.

NYHA Class III-Marked limitation in physical activity--Comfortable at rest, but less than ordinary physical activity causes fatigue, palpitation, dyspnea, or anginal pain. I am comfortable at rest but getting dressed makes me feel: tired, short of breath, like my heart beats too fast, like my heart beats irregularly,pressure in my chest, pain in my chest, tightness in my chest. NYHA Class IV-Inability to carry on any physical activity without discomfort or symptoms at rest. Any physical activity makes me feel: tired, short of breath, like my heart beats too fast, like my heart beats irregularly, pressure in my chest, pain in my chest, tightness in my chest.

The sample was previously characterized by functional limitation and is so described in Table 1. 


\section{RELATIONSHIPS BETWEEN COMPLIANCE BELIEFS AND FUNCTIONAL LIMITATIONS}

Hypothesis 1: There is a positive relationship between patients' functional limitations (designated by symptom stage/NYHA Class level) and perceptions of benefit from medication and dietary compliance (scores on Beliefs about Medication Compliance and Beliefs about Dietary Compliance Benefits subscales).

To recapitulate, a nonparametric test of correlation was applied between participants' functional limitations and each benefit subscale score (benefits of dietary and medication compliance) to test this hypothesis. The hypothesis is supported, strongly by a statistically significant positive relationship demonstrated between functional limitations and perceived benefits to medication compliance and with a "near" statistically significant positive relationship between functional limitations and perceived benefits to dietary compliance $(p=0.053)$ (See Table 11).Participant's symptom stage (functional limitation) positively correlated with Beliefs about Medication Compliance/total benefits subscale scores (Spearman's rho $=0.345, \mathrm{p}=0.007$, level of significance is .01 ) and came close to a statistically significant positive correlation with Beliefs about Dietary Compliance/total benefits subscale scores (Spearman's rho $=0.249, \mathrm{p}=0.53$, level of significance is .05). It is concluded that there is a positive relationship between patients' functional limitations and perceptions of benefit from medication and dietary compliance (See Table 11). Hypothesis 2: There is a negative relationship between patients' functional limitations (designated by symptom stage/NYHA Class level) and perceptions of barriers to medication and dietary compliance (scores on Beliefs about Medication Compliance and Beliefs about Dietary Compliance Barriers subscales). 
Again, nonparametric testing was applied between participants' reported functional limitations and each barriers to medication/dietary compliance subscale score. This hypothesis was supported, in part only ; a statistically significant correlation between functional limitations and perceived barriers to medication compliance was demonstrated. No significant relationship between functional limitations and perceived barriers to dietary compliance was found. A statistically significant negative correlation was found between participants' symptom stage(functional level) and Beliefs about Medication Compliance/ total barriers subscale scores (Spearman's rho $=-0.310, p=0.015$, level of significance is $.05)$ while symptom stage and Beliefs about Dietary Compliance/total barriers subscale scores were not found to correlate with statistical significance here.

It is concluded that there is a negative relationship between patients' functional limitations and perceptions of barrier to medication compliance (See Table 11). 
Table 11 Correlations between functional limitations (symptom stage) and therapeutic regimen compliance beliefs (subscale mean scores)

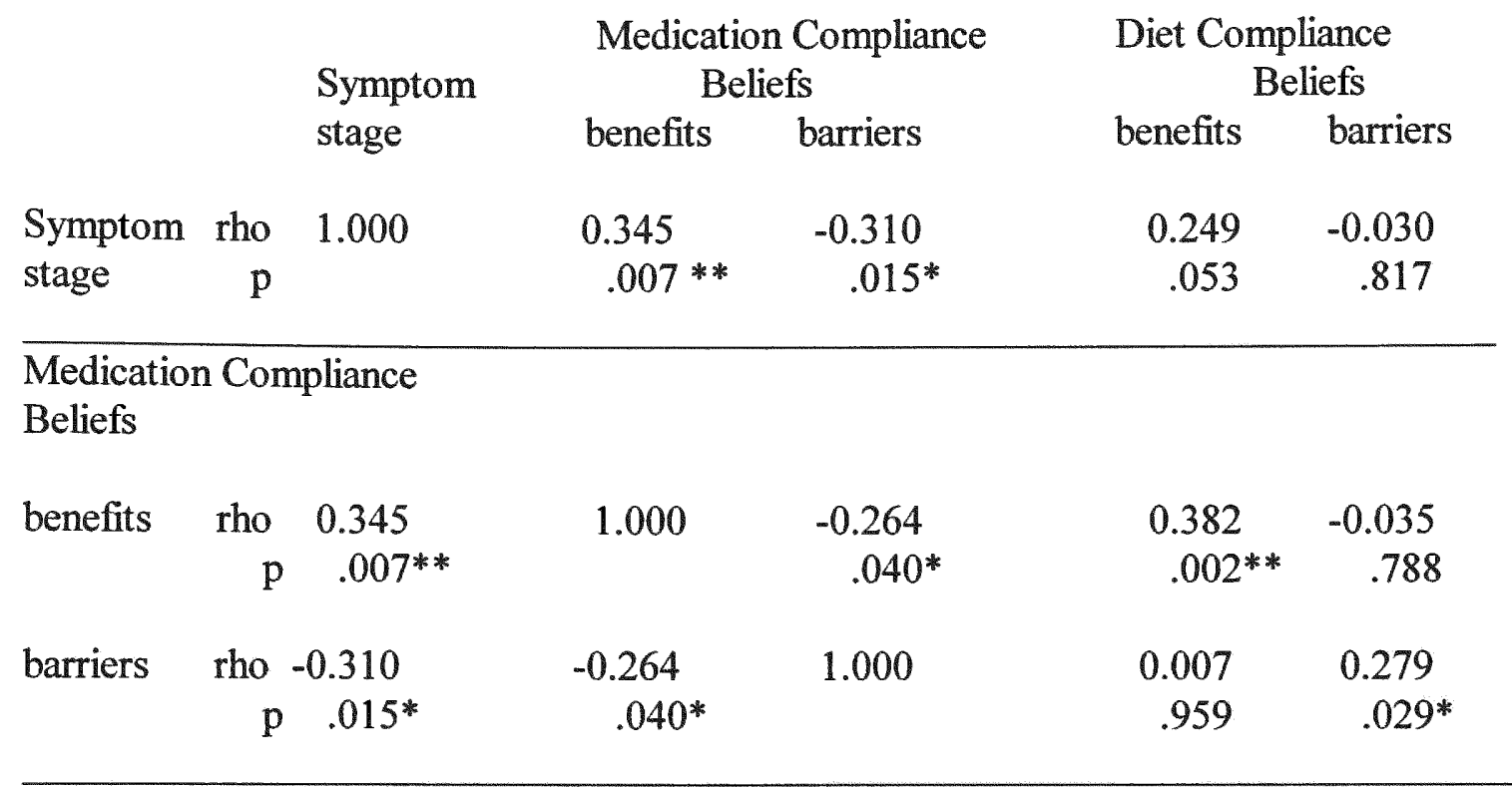

Diet Compliance

Beliefs

$\begin{array}{rrrrrrr}\text { benefits } & \text { rho } & 0.249 & 0.382 & 0.007 & 1.000 & -0.177 \\ & \mathrm{p} & .053 & .002 * * & .959 & & .172\end{array}$

$\begin{array}{rrrrrr}\text { barriers } & \text { rho }-0.030 & -0.035 & 0.278 & -0.177 & 1.000 \\ & \mathrm{p} .817 & .788 & .029^{*} & .172 & \end{array}$

${ }^{*} \mathrm{p}=.05$ significant

$* * \mathrm{p}=.01$ highly significant

Additional relationships emerged from data analysis. Beliefs about Medication Compliance/ total benefits subscale scores negatively correlated with Beliefs about Medication Compliance/ total barriers subscale scores (Spearman's rho $=-0.264, \mathrm{p}=0.040$, level of significance is .05) and positively correlated with Beliefs about Dietary Compliance/ total benefits subscale scores (Spearman's rho $=0.382, p=0.002$, level of significance is .01). Beliefs about Medication Compliance/ total barriers subscale scores 
positively correlated with Beliefs about Dietary Compliance/ total barriers subscale scores (Spearman's rho $=0.279, p=0.029$, level of significance is .05 ). No other correlations between therapeutic regimen compliance beliefs benefits/barriers subscale scores were found statistically significant (See Table 11).

Research question 4: What is the relationship between functional limitations and beliefs about medication and dietary compliance in terms of perceived benefits and barriers?

The relationships between functional limitation and individual benefit and barrier items on both Compliance Scales (Medication and Dietary) were measured (See Tables 12, 14, 16, and 18). All testing was two-tailed. Additionally, correlations between belief items in each subscale were demonstrated and are depicted in Tables 13, 15, 17 and 19 , respectively.

Five items on the Beliefs about Medication Compliance Scale are coded as perceived benefits to medication compliance and two of these individual items ( "If I take my water pills I will lower my chance of being in the hospital"--Spearman's rho $=0.477, \mathrm{p}=.000$, level of significance $=.001$ and "Taking my water pills lessens my swelling"--Spearman's rho $=0.394, p=.002$, level of significance $=.01$ ) positively correlate with functional limitation . 
Table 12 Correlations between functional limitation (symptom stage) and perceived benefits of medication compliance

\begin{tabular}{|c|c|c|c|c|c|c|c|}
\hline & & \multirow{2}{*}{$\begin{array}{l}\text { Symptom } \\
\text { Stage }\end{array}$} & \multicolumn{3}{|c|}{ BMCS perceived benefits } & \multirow[b]{2}{*}{$\# 4$} & \multirow[b]{2}{*}{$\# 5$} \\
\hline & & & $\# 1$ & \#2 & $\# 3$ & & \\
\hline Symptom & rho & 1.000 & 0.062 & 0.477 & 0.394 & 0.120 & 0.189 \\
\hline Stage & $\mathrm{p}$ & & .635 & $.000 * * *$ & $.002 * *$ & .357 & .145 \\
\hline \multicolumn{8}{|l|}{ BMCS } \\
\hline \multicolumn{8}{|l|}{ Benefits } \\
\hline \multirow[t]{2}{*}{$\# 1$} & rho & 0.062 & 1.000 & 0.287 & 0.096 & 0.280 & 0.014 \\
\hline & $\mathrm{p}$ & .635 & & $.025^{*}$ & .462 & $.029^{*}$ & .913 \\
\hline \multirow[t]{2}{*}{ \#2 } & rho & 0.477 & 0.287 & 1.000 & 0.356 & 0.345 & 0.256 \\
\hline & $\mathrm{p}$ & $.000 * * *$ & $.025 *$ & & $.005^{* *}$ & $.006 * *$ & $.046^{*}$ \\
\hline \multirow[t]{2}{*}{ \#3 } & rho & 0.394 & 0.096 & 0.356 & 1.000 & 0.302 & 0.258 \\
\hline & $\mathrm{p}$ & $.002 * *$ & .462 & $.005^{* *}$ & & $.018^{*}$ & $.045^{*}$ \\
\hline \multirow[t]{2}{*}{$\# 4$} & rho & 0.120 & 0.280 & 0.345 & 0.302 & 1.000 & 0.225 \\
\hline & $\mathrm{p}$ & .357 & $.029 *$ & $.006 * *$ & $.018^{*}$ & & .081 \\
\hline \multirow[t]{2}{*}{ \#5 } & rho & 0.189 & 0.014 & 0.256 & 0.258 & 0.225 & 1.000 \\
\hline & $\mathrm{p}$ & .145 & .913 & $.046^{*}$ & $.045^{*}$ & .081 & \\
\hline BMCS & \multicolumn{7}{|c|}{ Beliefs about Medication Compliance Scale } \\
\hline \multicolumn{8}{|c|}{ Benefits } \\
\hline \multirow{5}{*}{\multicolumn{8}{|c|}{$\begin{array}{l}\text { \# } 1 \text { When I take my water pills, I do not worry as much about my heart disease } \\
\text { \# } 2 \text { If I take my water pills, I will lower my chance of being in the hospital } \\
\text { \# } 3 \text { Taking my water pills lessens my swelling } \\
\text { \# } 4 \text { Taking my water pills helps me breathe better } \\
\text { \# } 5 \text { Taking my Medicine improves my quality of life }\end{array}$}} \\
\hline & & & & & & & \\
\hline & & & & & & & \\
\hline & & & & & & & \\
\hline & & & & & & & \\
\hline \multicolumn{8}{|c|}{$* \quad \mathrm{p}=.05$ significant } \\
\hline \multicolumn{8}{|c|}{ ** $\mathrm{p}=.01$ highly significant } \\
\hline$* * * \mathrm{p}=.001$ & very & ighly signific & & & & & \\
\hline
\end{tabular}

Tests of correlation also revealed 7 statistically significant relationships between benefit items as depicted in Table 13. 


\section{Table 13 Correlations between perceived benefits of medication compliance}

"When I take my water pills, I don't worry as much about my heart disease" correlates with:

"If I take my water pills, I will lower my chance of being in the hospital"

"Taking my water pills helps me breathe better"

"If I take my water pills I will lower my chance of being in the hospital" correlates with:

"Taking my water pills lessens my swelling"

"Taking my water pills helps me breathe better"

"Taking my medicine improves my quality of life"

"Taking my water pills lessens my swelling" correlates with:

"Taking my water pills helps me breathe better"

"Taking my medicine improves my quality of life"

Seven items are coded as perceived barriers on the Beliefs about Medication Compliance Scale and 4 of these demonstrate statistically significant negative correlations with functional limitation ("Taking water pills is hard to remember"--Spearman's rho= $-0.305, p=.017$, level of significance $=.05$, "I have to take too many water pills each day"--Spearman's rho $=-.0513, \mathrm{p}=.000$, level of significance $=.001$, "I forget to take my water pills"--Spearman's rho $=-0.302, \mathrm{p}=.018$, level of significance $=.05$, and "Taking water pills makes me worry about my heart disease"--Spearman's rho=-0.290, $p=.023$, level of significance $=.05)$. 
Table 14 Correlations between functional limitation (symptom stage) and perceived barriers to medication compliance

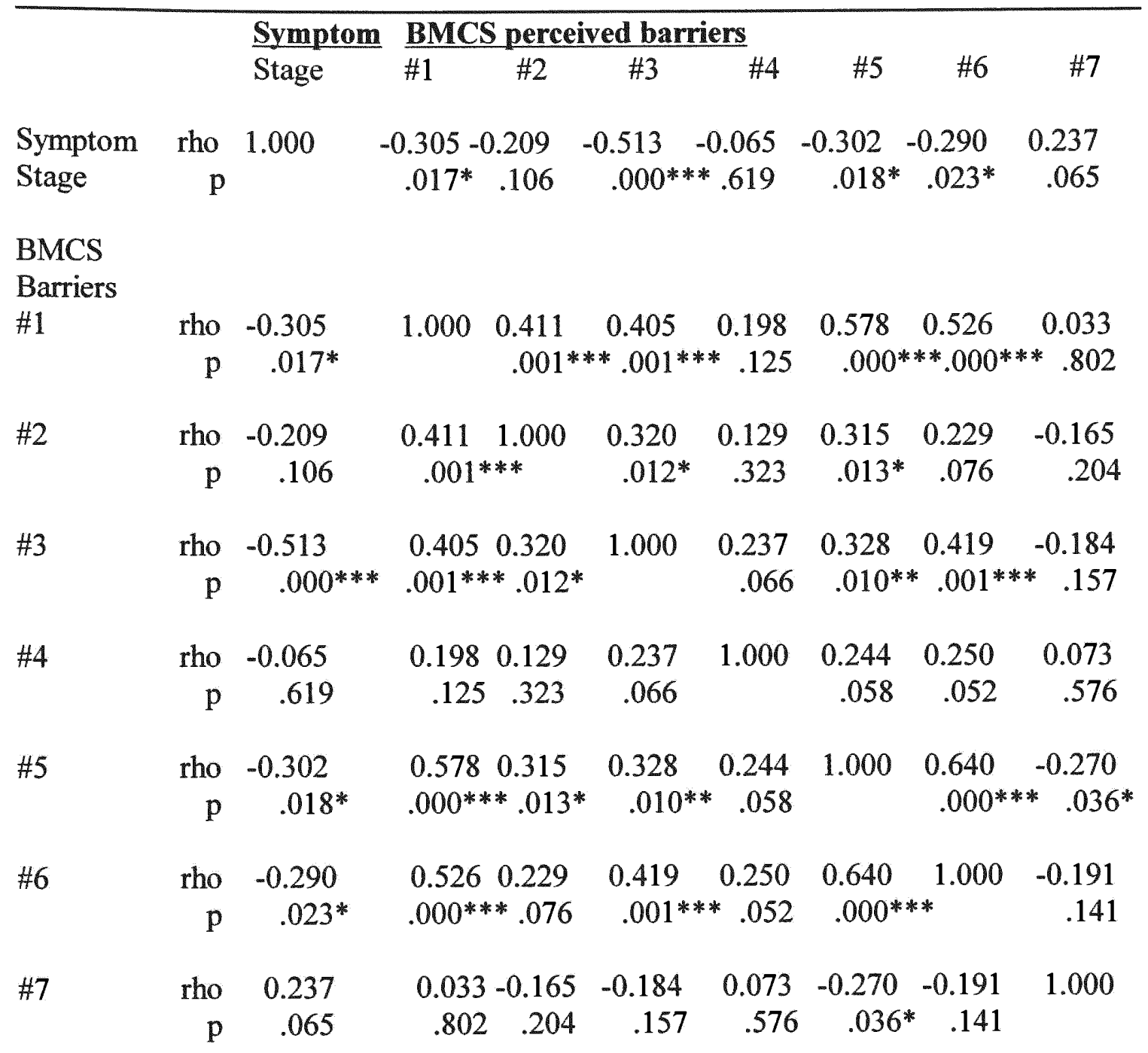

BMCS Beliefs about Medication Compliance Scale

Barriers

\#1 Taking water pills is hard to remember

\#2 Taking water pills is unpleasant

\#3 I have to take too many water pills each day

\#4 Taking water pills makes it hard for me to go away from home

\#5 I forget to take my water pills

\#6 Taking water pills makes me worry about my heart disease

\#7 Taking water pills wakes me up at night to go to the bathroom $\left({ }^{*} \mathrm{p}=.05\right.$

significant, ${ }^{* *} \mathrm{p}=.01$ highly significant, ${ }^{* * *} \mathrm{p}=.001$ very highly significant) 
Statistically significant relationships between barrier items are also revealed with tests of correlation as depicted in Table 15.

\section{Table 15 Correlations between perceived barriers to medication compliance}

"Taking water pills is hard to remember" correlates with:

"Taking water pills is unpleasant"

"I have to take too many water pills each day"

"I forget to take my water pills"

"Taking water pills makes me worry about my heart disease"

"Taking water pills is unpleasant"

correlates with:

"I have to take too many water pills each day"

"I forget to take my water pills"

"I have to take too many water pills each day" correlates with:

"I forget to take my water pills"

"Taking water pills makes me worry about my heart disease"

"I forget to take my water pills" correlates with:

"Taking water pills makes me worry about my heart disease" "Taking water pills wakes me up at night to go to go to the bathroom"

Six items on the Beliefs about Dietary Compliance Scale are coded as perceived benefits to dietary compliance; one of these individual items correlates strongly with functional limitation ("Eating a low salt diet will keep me healthy"--Spearman's rho $=0.275, \mathrm{p}=.032$, level of significance $=.05$ ). A second subscale item ("Eating a low salt diet will keep my heart healthy"--Spearman's rho=0.234, $p=.070$ ) correlates marginally with functional limitation. 


\section{Table 16 Correlations between functional limitation (symptom stage) and perceived benefits to dietary compliance}

\begin{tabular}{|c|c|c|c|c|c|c|c|c|}
\hline & & Symptom & $\mathrm{BDCS} p$ & perceived be & enefits & & & \\
\hline & & Stage & $\# 1$ & $\# 2$ & \#3 & $\# 4$ & $\# 5$ & \#6 \\
\hline Symptom & rho & 1.000 & 0.275 & 0.234 & 0.210 & 0.118 & 0.011 & 0.199 \\
\hline Stage & $\mathrm{p}$ & & $.032 *$ & .070 & .104 & .366 & .933 & .124 \\
\hline BDCS & & & & & & & & \\
\hline Benefits & & & & & & & & \\
\hline$\# 1$ & rho & 0.275 & 1.000 & 0.660 & 0.658 & 0.388 & 0.052 & 0.128 \\
\hline & $\mathrm{p}$ & $.032 *$ & & $.000 * * *$ & $.000 * * *$ & $.002 * *$ & .691 & .325 \\
\hline$\# 2$ & rho & 0.234 & 0.660 & 1.000 & 0.515 & 0.405 & 0.054 & 0.189 \\
\hline & $\mathrm{p}$ & .070 & $.000 * * *$ & & $.000 * * *$ & $.001 * * *$ & .680 & .144 \\
\hline$\# 3$ & rho & 0.210 & 0.658 & 0.515 & 1.000 & 0.560 & 0.093 & 0.127 \\
\hline & $\mathrm{p}$ & .104 & $.000 * * *$ & $.000 * * *$ & & $.000 * * *$ & .478 & .330 \\
\hline$\# 4$ & rho & 0.118 & 0.388 & 0.405 & 0.580 & 1.000 & 0.111 & 0.230 \\
\hline & $\mathrm{p}$ & .366 & $.002 * *$ & $.001 * * *$ & $.000 * * *$ & & .394 & .074 \\
\hline \#5 & rho & 0.011 & 0.052 & 0.054 & 0.093 & 0.111 & 1.000 & 0.388 \\
\hline & $\mathrm{p}$ & .933 & .691 & .680 & .478 & .394 & & $.002 * *$ \\
\hline \#6 & rho & 0.199 & 0.128 & 0.189 & 0.127 & 0.230 & 0.388 & 1.000 \\
\hline & $\mathrm{p}$ & .124 & .325 & .144 & .330 & .074 & $.002 * *$ & \\
\hline BDCS Bel & s abou & Dietary Co & mpliance S & Scale & & & & \\
\hline Benefits & & & & & & & & \\
\hline \#1 Eating & ow sal & diet will ke & p me heal & lthy & & & & \\
\hline \#2 Eating & ow sal & diet will $\mathrm{ke}$ & p my hear & rt healthy & & & & \\
\hline \#3 Eating & ow sal & diet will ke & p my swel & lling down & & & & \\
\hline \#4 Eating & ow sal & diet will ke & $\mathrm{p}$ fluid fro & om building & up in my b & body & & \\
\hline \#5 When I & llow $\mathrm{r}$ & y low salt $d$ & et, I feel b & better & & & & \\
\hline \#6 Eating & ow sal & diet will he & p me breat & the easier & & & & \\
\hline${ }^{*} \mathrm{p}=.05 \mathrm{sig}$ & ficant & & & & & & & \\
\hline$* * p=.01 \mathrm{~h}$ & aly sig & ficant & & & & & & \\
\hline$* * * \mathrm{p}=.00$ & very hi & hly significa & & & & & & \\
\hline
\end{tabular}


Additionally, statistically significant relationships are demonstrated between benefit items of the Beliefs about Dietary Compliance Scale (See Table 17).

\section{Table 17 Correlations between perceived benefits of dietary compliance}

"Eating a low salt diet will keep me healthy" correlates with:

"Eating a low salt diet will keep my heart healthy"

"Eating a low salt diet will keep my swelling down"

"Eating a low salt diet will keep fluid from building up in my body"

"Eating a low salt diet will keep my heart healthy" correlates with:

"Eating a low salt diet will keep my swelling down"

"Eating a low salt diet will keep fluid from building up in my body"

"Eating a low salt diet will keep my swelling down" correlates with:

"Eating a low salt diet will keep fluid from building up in my body"

"When I follow my low salt diet, I feel better" correlates with:

"Eating a low salt diet will help me breathe easier"

Of the six items on the Beliefs about Dietary Compliance Scale coded as perceived barriers to dietary compliance, only one of these individual items correlates significantly with functional limitation ("Salty food is not good for me"--Spearman's rho=0.348**, $\mathrm{p}=.006$, level of significance $=.01$ ). A few significant relationships between barrier items to dietary compliance were also revealed (See Tables 18 and 19). 


\section{Table 18 Correlations between functional limitation (symptom stage) and perceived barriers to dietary compliance}

\begin{tabular}{|c|c|c|c|c|c|c|c|c|}
\hline & \multicolumn{4}{|c|}{ Symptom BDCS perceived barriers } & \multirow[b]{2}{*}{$\# 4$} & \multirow[b]{2}{*}{$\# 5$} & \multirow[b]{2}{*}{ \#6 } \\
\hline & & Stage & $\# 1$ & $\# 2$ & \#3 & & & \\
\hline Symptom & rho & 1.000 & 0.348 & -0.015 & -0.016 & -0.123 & -0.142 & -0.057 \\
\hline Stage & $\mathrm{p}$ & & $.006^{* *}$ & .906 & .902 & .345 & .275 & .662 \\
\hline \multicolumn{9}{|l|}{$\begin{array}{l}\text { BDCS } \\
\text { Barriers }\end{array}$} \\
\hline \multirow[t]{2}{*}{$\# 1$} & rho & 0.348 & 1.000 & -0.126 & -0.271 & -0.057 & -0.130 & -0.101 \\
\hline & $\mathrm{p}$ & $.006 * *$ & & .332 & $.035 *$ & .665 & .318 & .440 \\
\hline \multirow[t]{2}{*}{ \#2 } & rho & -0.015 & -0.126 & 1.000 & 0.227 & 0.221 & 0.161 & 0.219 \\
\hline & $\mathrm{p}$ & .906 & .332 & & .078 & .087 & .214 & .090 \\
\hline \multirow[t]{2}{*}{$\# 3$} & rho & -0.016 & -0.271 & 0.227 & 1.000 & 0.330 & 0.077 & 0.251 \\
\hline & $\mathrm{p}$ & .902 & $.035^{*}$ & .078 & & $.009 * *$ & .558 & .051 \\
\hline \multirow[t]{2}{*}{$\# 4$} & rho & -0.123 & -0.057 & 0.221 & 0.330 & 1.000 & 0.557 & 0.378 \\
\hline & $\mathrm{p}$ & .345 & .665 & .087 & $.009 * *$ & & $.000 * * *$ & $* .003 * *$ \\
\hline \multirow[t]{2}{*}{$\# 5$} & rho & -0.142 & -0.130 & 0.161 & 0.077 & 0.557 & 1.000 & 0.248 \\
\hline & $\mathrm{p}$ & .275 & .318 & .214 & .558 & $.000 * * *$ & & .054 \\
\hline \multirow[t]{2}{*}{ \#6 } & rho & -0.057 & -0.101 & 0.219 & 0.251 & 0.378 & 0.248 & 1.000 \\
\hline & $\mathrm{p}$ & .662 & .440 & .090 & .051 & $.003 * *$ & .054 & \\
\hline
\end{tabular}

BDCS Beliefs about Dietary Compliance Scale Barriers

\#1 Salty food is not good for me

\#2 I cannot go out to many places to eat because of the low salt diet

\#3 Food does not tast good on the low salt diet

\#4 Following a low salt diet costs too much money

\#5 Following a low salt diet takes too much time

\#6 Following a low salt diet is too hard to understand

${ }^{*} \mathrm{p}=.05$ significant

$* * \mathrm{p}=.01$ highly significant

$* * * p=.001$ very highly significant 
Table 19 Correlations between perceived barriers to dietary compliance

"Salty food is not good for me"

correlates with:

"Food does not taste good on the low salt diet"

"Food does not test good on the low salt diet" correlates with:

"Following a low salt diet costs too much money"

"Following a low salt diet costs too much money" correlates with:

"Following a low salt diet takes too much time"

"Following a low salt diet is too hard to understand"

66 


\section{CHAPTER V \\ DISCUSSION}

\section{DISCUSSION AND COMPARISONS}

This chapter discusses study findings and compares relevant findings to Bennett et al's 1997 instrument development study. Nursing implications, study limitations and recommendations for further nursing study are herein noted.

To recapitulate, the purpose of this study was to determine the extent of relationship between heart failure patients beliefs about compliance with therapeutic regimen and their functional limitations. To that end, patients at a specialized outpatient clinic in South Florida were recruited by meeting the inclusion criteria of Bennett's study. Participants were asked to report their functional limitations indicating presence of or experience with symptoms ( Health Belief Model variable of perceived susceptibility/severity). Participants were also asked to indicate their response to scale items derived by Bennett et al. from the Health Belief Model (HBM) to measure beliefs about compliance with medication and diet ( variables of perceived benefits and perceived barriers to recommended health actions). The Health Belief Model (Becker, 1974) and the Bennett investigators suggest that heart failure patients' compliance beliefs may differ according to their classification level of disease. The findings of this study lend support to that suggestion.

In a review of published research regarding compliance with therapeutic regimen, Sacket and Haynes (1976) found that symptomatic patients showed higher compliance rates, regardless of the method by which compliance with therapeutic regimen was operationalized. As previously noted, perceived benefits and barriers were maintained as variables associated with the likelihood of prescribed regimen compliance in sick role 
behavior as per Becker and Becker \& Maiman studies of the mid 1970's. Maiman, Becker, Kirscht, Haefner and Drachman (1977) applied the HBM to chronic illness behavior in a study of long term therapeutic regimen compliance as diet modification and found that individual's compliance behaviors correlated with measured health beliefs. Can an assessment of compliance beliefs and what relates to them, as undertaken in the present study, provide some predictive value for the health care provider as to likelihood of patient following recommended health action or perhaps, the converse is true? Sackett and Haynes (1976) found some evidence to suggest that compliance behavior changes precede health belief changes. The Health Belief Model and those findings underscored above provide the theoretic underpinnings for this work.

Compliance Beliefs

Compliance beliefs of heart failure patients were measured using Bennett et al's instruments developed for this purpose. As compared to Bennett's sample,the present sample was smaller in size, more culturally diverse, less functionally limited and slightly younger. Males also comprised the majority of participants $(\mathrm{N}=101)$ in the Bennett study described therein racially, as primarily White. The majority of participants in the present study had a lesser degree of functional limitation than the majority of participants in Bennett et al.'s study. Conversely, $37 \%$ of Bennett et al's study participants combined were identified as having NYHA Class I and Class II limitations while $63 \%$ of their participants combined, the majority, were identified as having more severe functional limitations; NYHA Class III and Class IV. Bennett's sample reflected a slightly broader age range and older participant by mean age than the present study. These attributes may 
or may not be relevant in the comparison of our study findings. With a larger sample size $(N=98$ versus 61$)$ and slightly broader actual range of scores, Bennett's mean perceived benefit to medication compliance subscale score, for example (mean=19.84, $\mathrm{SD}=3.84$ ) is slightly higher than that of the present study. Bennett's mean perceived barrier to medication compliance subscale score (mean=13.07, $\mathrm{SD}=3.44$ ) is slightly lower as compared to the corresponding mean barrier subscale score obtained in the present study. Bennett's original instrument development study (1997) identified 7 items as perceived benefits to dietary compliance and 5 items as perceived barriers, two subscales of the Beliefs about Dietary Compliance Scale, completed by 101 participants. Mean subscale scores are relevant in context of comparison to Bennett's with perceived benefits to diet compliance greater and perceived barriers to diet compliance less than those mean subscale scores in this study. Bennett's mean perceived benefit subscale score (mean $=29.08, \mathrm{SD}=4.34$, possible range 7 to 35 ) was again higher than that of the present study. Similarly, Bennett's mean perceived barriers to dietary compliance subscale score (mean $=12.70, \mathrm{SD}=4.00$, possible range 5 to 25 ) as compared to the corresponding mean score obtained in the present study, was again lower. Actual ranges of subscale scores for participant perceived benefits of and barriers to dietary compliance are 17 to 35 and 5 to 23, respectively; slighter broader than for my smaller sample. It is undetermined whether or not the greater perceived benefits to therapeutic regimen compliance by mean score and the lesser perceived barriers to therapeutic regimen by mean score are statistically significant in their difference to the present study. 
The item most highly perceived as a benefit to medication compliance in this sample is improved quality of life with lower chances of being hospitalized and less swelling subsequently identified in rank order as perceived benefits, respectively. All three items, thereby may be considered of clinical significance for this sample. The benefit item ranked most highly ("Taking my medicine improves my quality of life") did not correlate with functional limitation. This lack of correlation may suggest that the benefit is perceived so greatly as to apply to all heart failure patients, superseding symptom level. It is also, notably, the only generic versus diuretic medication compliance item measured here.

Items coded as benefits to medication compliance and found equivocal as perceived by this sample group were decreased worry about heart disease and better breathing. These items may be labeled as equivocal benefits since participants' negative and undecided responses to them closely rivaled their item agreement. It may be important to recall that the majority of the sample self identified as NYHA Class I and II and therefore were perhaps better compensated with less worry where difficulty breathing was not a primary manifestation of their heart failure. It is also possible that this sample is just less representative of pulmonary congestive features.

Diuretic therapy was the primary theme of the Beliefs about Medication Compliance Scale. Number of pills to be taken, complexity of regimen and access to pharmacy services have been cited in the compliance literature as previously noted and by this sample group, in informal discussion during data collection, as barriers to compliance with medication regimen.

The majority of participants in this sample did not perceive the items below 
as great barriers to medication compliance, primarily compliance with diuretic therapy, as previously noted, with the exception of "Taking water pills wakes me up at night to go to the bathroom" to which a majority of participants responded positively.

1. Taking water pills makes me wake up at night to go to the bathroom $(52.5 \%)$

2. Taking water pills makes it hard for me to go away from home (24.6\%)

3. Taking water pills is unpleasant $(18.1 \%)$

4. I forget to take my water pills $(14.8 \%)$

5. Taking water pills is hard to remember $(9.8 \%)$

6. Taking water pills makes me worry about my heart disease (4.9\%)

Perhaps, heart failure patients managed in a specialized outpatient clinic may be more compliant as a group perceiving less barrier to the traditional negatives associated with diuretic therapy or these preselected items centering on diuretic therapy do not adequately reflect the barriers to medication compliance perceived in this group.

Overall, benefits to dietary compliance were strongly perceived by this sample with the exception of a low salt diet perceived not as strongly as a preventive of breathing difficulty. Again, with the majority of patients less symptomatic and/or better compensated, perhaps pulmonary congestion/respiratory manifestations are not prevalent. Though patients perceived the low salt diet as means to prevent fluid buildup they may not extend that concept to lung physiology.

Of 6 compliance with diet subscale items, only one ("Salty food is not good for me") was perceived strongly as a compliance barrier with a large percentage of participants indicating agreement to the item.

1. Salty food is not good for me $(95.1 \%)$

2. I cannot go out to many places to eat because of the low salt diet $(49.2 \%)$

3. Food does not taste good on the low salt diet (45.9\%)

4. Following a low salt diet costs too much money (24.6\%)

5. Following a low salt diet is too hard to understand (16.4\%) 
6. Following a low salt diet takes too much time (14.7\%)

The majority of responses for each of the barriers "Following a low salt diet costs too much money, "Following a low salt diet takes too much time" and "Following a low salt diet is too hard to understand" were negative. The majority of participants in this sample, thereby, did not perceive these items as great barriers to dietary compliance.

Items "I cannot go out to many places too eat because of the low salt diet" and "Food does not taste good on the low salt diet" are equivocal barriers to low salt diet compliance, at best, as negative responses rival positive responses to each item. By informal interview, many patients noted an "adjustment period" to incorporate the low sodium diet. Perhaps the overall low perception of these items as diet compliance barriers are secondary to the ubiquitous media messaging to eat healthy and mainstreaming into popular culture of designer foods and special diets. The possibility may again be entertained that specially managed heart failure patients have better regimen understanding, knowledge and compliance.

Functional limitations

As noted previously, the NYHA classification system whereby one of four functional classes is assigned to cardiac patients according to the degree of effort needed for their symptom manifestation, has been criticized as subjective.

The consensus recommendations of the Advisory Council to Improve Outcomes

Nationwide in Heart Failure (ACTION HF) (1999) cites the NYHA classification system as having a high degree of interobserver variability and as lacking the sensitivity to denote small but significant clinical status changes though it is the most commonly used gauge of 
symptom severity in the evaluation of clinical status. This guideline also recommends inquiry regarding symptoms experienced during activities of daily living and those that impair functional status. A strategy of NYHA classes transcribed to reflect symptoms experienced with activities of daily living was employed in this study to assess functional limitations among heart failure patients as supported by expert panel review. Variability may have been reduced by virtue of the fact that participants self reported symptoms. Treatment of heart failure must, by necessity, be two pronged because symptom evolution is known to be only weakly related to evolving cardiac dysfunction therefore improving functional capacity alone is inadequate. A goal of treatment must also be decreasing disease progression. Assessment of functional limitation as a measure of clinical status is a "snapshot" of sorts; symptoms may change over time secondary to medication effects, disease progression, concurrent illness or even heart failure etiology. It is interesting to consider the individual heart failure patients functional limitations in light of etiology of disease; heart failure secondary to substance abuse (alcohol or cocaine cardiomyopathy) versus heart failure secondary to myocardial infarction from coronary artery disease versus heart failure secondary to viral cardiomyopathy, for example. In an assessment of patient perceived susceptibility/severity of heart failure, is patient's experience with invasive diagnostics and interventions a potential influence on compliance beliefs or behaviors?

The fact remains that as the most frequently used gauge of clinical status in clinical practice settings, as an outcome measure like worsening class level to denote a decompensation or improving level as post intervention measure of specialized 
management efficacy, this classification system has merit and staying power.

Relationships between functional limitations and compliance beliefs

It is concluded that there is a positive relationship between patients' functional limitations and perceptions of benefit from medication and dietary compliance. It is also concluded that there is a negative relationship between patients' functional limitations and perceptions of barrier to medication compliance. Though a single barrier to dietary compliance scale item positively correlates with functional limitation, it is not conclusive from this study to what extent functional limitation and perceptions of barrier to dietary compliance are related. That the presence of symptoms exerts an affect on a patient's perceived severity of illness charting a course for health action has been demonstrated (Becker, 1974; Becker and Maiman, 1975). Therefore, demonstrated relationships of symptom experience with other HBM variables like perception of benefit and barrier to a recommended health behavior merit continued study in the effort to mediate compliance (Becker and Maiman, 1975). Perceived benefits of compliance with medication by mean subscale score demonstrated positive correlation with functional limitations while perceived barriers to compliance with medication by mean subscale score demonstrated negative correlation with functional limitations. Statistically significant relationships of individual perceived benefits of medication compliance items ("If I take my water pills, I will lower my chance of being in the hospital" and "Taking my water pills lessens my swelling") with functional limitations are logical and well demonstrated in this study. It may be easily recognized that the more symptomatic patient would construe benefit from decreased hospitalizations and less swelling. Demonstrated interitem correlations on the 
Beliefs about Medication Compliance Scale are again, logical on review. That these items exist as perceived benefits/barriers to compliance and demonstrate relationships, may be useful in the assessment of a heart failure patient's overall compliance belief set.

Compliance belief relationships may be important to individualizing patient teaching. This study demonstrates individual barriers to compliance with medication compliance items ("Taking water pills is hard to remember", "I have to take too many water pills each day", "Taking water pills makes me worry about my heart disease" and "I forget to take my water pills") are negatively correlated with functional limitation; again logical in that the more symptomatic patient may perceive less barrier to medication compliance.

Regarding beliefs about dietary compliance, benefits subscale mean scores are close to significantly correlated with functional limitation. If sample size were greater, statistical significance may be demonstrated. No relationship with barriers to diet compliance subscale mean scores is demonstrated here but preselected items were not perceived greatly as barriers to dietary compliance in this sample. Clinically, therefore, the potential for functional limitations to be related/influence perceived barriers to diet compliance, may not be excluded. Individual benefits to diet compliance ("Eating a low salt diet will keep me healthy" and "Eating a low salt diet will keep my heart healthy") demonstrate strong and marginal positive correlation respectively, with functional limitation in this study. Individual barriers to dietary compliance item ("Salty food is not good for me") demonstrates strong positive correlation with functional limitation in this study. In conclusion, the Health Belief Model and the Bennett investigators in their 
instrument development study (1997) to measure compliance beliefs among heart failure patients suggest those beliefs may differ according to patient's class of disease. The findings of this small, pilot study support that suggestion.

Study power is only adequate (greater than .80 by convention) if a large effect size is considered with this small sample $(\mathrm{N}=61$, delta $=.50$, power $=.96)$. A large effect size was chosen by the principal investigator since Health Belief Model (HBM) variable testing is not a new area of research and a review of the vast body of compliance literature is supportive of the HBM variables, their relationships and influences on compliance beliefs and behaviors. This investigator's clinical practice experience also supports the assumption that symptoms' experience influences patients' compliance beliefs and behaviors.

\section{IMPLICATIONS}

It is well known and revealed herein that compliance beliefs and behaviors are highly complex. Implications for nursing practice are clear. Heart failure is a widespread and growing problem. The latest consensus recommendations of the Advisory Council to Improve Outcomes Nationwide in Heart Failure (ACTION HF, 1999) identify treatment goals for this clinical syndrome; all of which may be mediated by patient compliance with therapeutic regimen. This implies the necessity of strong consideration for patient compliance issues and influences in nursing practice, education and in our efforts to educate heart failure patients. Assessment of patients' beliefs is necessary to increase patient involvement in the management of their chronic illness (Given et al, 1983). Problems of health related behavior, like poor compliance with a low salt diet, for 
example, may be considered as symptoms leading the nurse to a behavioral diagnosis. Again, thorough assessment of compliance beliefs and what may relate to those, is the starting point for making a diagnosis and ultimately implementing treatment interventions aimed at modifying compliance behaviors. (Jenkins, 1979).

\section{LIMITATIONS}

1. Small sample size, so study lacks power.

2. Non random sample selection risking bias and erroneous findings.

3.Purely quantitative design with preselected benefit/barrier items limits potential findings especially as the psychosocial nature of compliance beliefs increases their complexity and variability among individuals, even those with a common illness.

\section{RECOMMENDATIONS}

1. Use power analysis to determine adequate sample size for various effect sizes in order to increase study power. The present study has strong clinical significance and a solid theoretical basis which merits its repetition with a sample of at least 101 heart failure patients ( With level of significance $=.05$, two tailed testing: $N=101$, medium effect size $=$ .30 yields power $=.85 ; \mathrm{N}=801$, small effect size $=.10$, yields power $=.80$ )

2. Randomize selection of heart failure patients for further study of HBM variables influence on compliance beliefs and behaviors by selecting a sampling frame like a large outpatient heart failure clinic, obtain a list of current patients, number them consecutively and using a table of random numbers, draw at random, a sample of the desired size.

3. Triangulate the study design to obtain qualitative themes of benefit/barrier to compliance with therapeutic regimen. 
4. Test further the reliability and validity of NYHA classification system for cardiac disease as adapted in this study.

5. Assess patients' functional limitations and compliance beliefs as baseline to customize teaching directed at influencing therapeutic regimen compliance.

6. Assess patients' experience with invasive diagnostics/interventions as potential influences on perceived susceptibility/severity variable of HBM .

7. Increase nursing knowledge of patient compliance with therapeutic regimen: as individual practitioners, and as a professional body, in the effort to affect positive change in the treatment of chronic heart failure. Implement university curriculum and clinical education addressing compliance as a modifiable behavioral response set. 8. Increase nursing knowledge of cultural, racial, and gender differences: as individual practitioners, and as a professional body, in order to provide competent preventive care, evaluation and management of heart failure. For example, develop and implement sensitive tools in multiple languages to assess potential cross cultural differences in compliance with low salt diet beliefs. 


\section{REFERENCES}

Advisory Council to Improve Outcomes Nationwide in Heart Failure (ACTION HF). (1999). Consensus recommendations for the management of chronic heart failure. The American Journal of Cardiology 83(2A), 1A-38A.

American College of Cardiology/American Heart Association Task Force (ACC/AHA TF). (1995). Guidelines for the evaluation and management of heart failure. Report of the American College of Cardiology/American Heart Association Task Force on practice guidelines (committee on evaluation and management of heart failure). Journal of the American College of Cardiology 26(5), 1376-1398.

Aronow, W.S. \& Tresch, D. (Series Eds.). (1997). Special series: Congestive heart failure in older persons. Treatment of congestive heart failure in older persons. Journal of the American Geriatrics Society 45, 1252-1258.

Baig, M.K., Mahon, N., McKenna, W.J., Caforio, A.L.P., Bonow, R.O., Francis, G.S., \& Gheorghiade, M. (1998). The pathophysiology of advanced heart failure. American Heart Journal 135, S216-S230.

Becker, M.H. (1974). The health belief model and sick role behavior. Health Education Monographs 2(4), 409-419.

Becker, M.H. (1985). Patient adherence to prescribed therapies. Medical Care 23(5), 539-555.

Becker, M.H., Haefner, D.P., Maiman, L.A., Kirscht, J.P., \& Drachman, R.H. (1977). The health belief model and prediction of dietary compliance: A field experiment. Journal of Health and Social Behavior 18, 348-366.

Becker, M.H. \& Maiman, L.A. (1975). Sociobehavioral determinants of compliance with health and medical care recommendations. Medical Care 13 (1), 10-24.

Bennett, S.J., Huster, G.A., Baker, S.L., Milgrom, L.B., Kirchgassner, A., Birt, J., \& Pressler, M.L. (1998). Characterization of the precipitants of hospitalization for heart failure decompensation. American Journal of Critical Care 7. 168-174.

Bennett, S.J., Milgrom, L.B., Champion, V. \& Huster, G.A. (1997). Beliefs about medication and dietary compliance in people with heart failure; An instrument development study. Heart \& Lung 26(4), 273-279.

Buschnell, F.K.P., (1992). Self-Care teaching for congestive heart failure patients. Journal of Gerontological Nursing 18(10), 27-32. 
Cameron, C. (1996). Patient compliance: Recognition of factors involved and suggestions for promoting compliance with therapeutic regimens. Journal of Advanced Nursing 24, 244-250.

Centers for Disease Control and Prevention. U.S. Department of Health and Human Services. Public Health Service. Mortality from congestive heart failure-United States, 1980-1990. Morbidity and Mortality Weekly Report 43(5), 77-81.

Center for Health Promotion and Education. Center for Disease Control. (1982). Strategies to Promote Self Management of Chronic Disease. U.S. Public Health Service. Department of Health and Human Services.

Chin, M.H. \& Goldman, L. (1997). Correlates of early hospital readmission or death in patients with congestive heart failure. American Journal of Cardiology 79, 1640-1644.

Cody, R.J., Torre, S., Clark, M. \& Pondolfino, K. (1989). Age-related hemodynamic, renal and hormonal differences among patients with congestive heart failure. Archives of Internal Medicine 149, 1023-1028.

Cohn, J.N. (1996). The management of chronic heart failure. The New England Journal of Medicine 335(7), 490-498.

Cohn, J.N., Johnson, G., Ziesche, S., Cobb, F., Francis, G., Tristani, F., Smith, R., Dunkman, W.B., Loeb, H., Wong, M., Bhat, G., Goldman, S., Fletcher, R.D., Doherty, J., Hughes, V., Carson, P., Cintron, G., Shabetai, R. \& Haakenson, C. (1991). A comparison of enalapril with hydralazine-isosorbide dinitrate in the treatment of chronic congestive heart failure. The New England Journal of Medicine 325(5), 303-310.

Cummings, K.M. Kirscht, J.P., Becker, M.H., \& Levin, N.W. (1984). Construct validity comparisons of three methods for measuring patient compliance. Health Services Research 19(1), 103-116.

DiMatteo, M.R., Sherbourne, C.D., Hays, R.D., Ordway, L., Kravitz, R.L., McGlynn, E.A., Kaplan, S., \& Rogers, W.H. (1993). Physicians' characteristics influence patients'dherence to medical treatment: Results from the Medical Outcomes Study. Health Psychology 12(2), 93-102.

Dracup, K., Baker, D.W., Dunbar, S.B., Dacey, R.A., Brooks, N.H., Johnson, J.C., Oken, C., \& Massie, B.M. (1994). Management of heart failure. II. Counseling, education and lifestyle modifications. Journal of the American Medical Association 272(18), 1442-1446. 
Elder, J.P., Ayala, G.X., Harris, S. (1999). Theories and intervention approaches to health-behavior change in primary care. American Journal of Preventive Medicine 17(4), 275-284.

Fletcher, S.W., Pappius, E.M., \& Harper, S.J. (1979). Measurement of medication compliance in a clinical setting. Archives of Internal Medicine 139, 635-638.

Fonarow, G.C., Stevenson, L.W., Walden, J.A., Livingston, N.A., Steimle, A.E., Hamilton, M.A., Moriguchi, J., Tillisch, J.H., \& Woo, M.A. (1997). Impact of a comprehensive heart failure management program on hospital readmission and functional status of patients with advanced heart failure. Journal of the American College of Cardiology 30, 725-732.

Francis, G.S., Benedict, C., Johnstone, D.E., Kirlin, P.C., Nicklos, J., Liang, C., Kubo, S.H., Rudin-Toretsky, E. \& Yusuf, S. (1990). Comparison of neuroendocrine activation in patients with left ventricular dysfunction with and without congestive heart failure. Circulation 82, 1724-1729.

Ghali, J.K., Kadakia, S., Cooper, R., \& Ferlinz, J. (1988). Precipitating factors leading to decompensation of heart failure. Archives of Internal Medicine 148, 2013-2016.

Given, C.W., Given, B.A., Gallin, R.S., \& Condon, J.W. (1983). Development of scales to measure beliefs of diabetic patients. Research in Nursing and Health 6. 127-141.

Goldberg, R. (1999). Assessing the population burden from heart failure. Need for sentinel population-based surveillance systems. Archives of Internal Medicine 159, 15-17.

Gravely, E.A., \& Oseasohn, C.S. (1991). Multiple drug regimens: medication compliance among veterans 65 years and older. Research in Nursing and Health 14 , 51-58.

Hagenhoff, B.D., Feutz, C., Conn, V.S., Sagehorn, K.K., \& Moranville-Hunziker, M.B. (1994). Patient education needs as reported by congestive heart failure patients and their nurses. Journal of Advanced Nursing 19, 685-690.

Haldeman, G.A., Croft, J.B., Giles, W.H., Rashidee, A. (1999). Hospitalization of patients with heart failure: National hospital discharge survey, 1985 to 1995 . American Heart Journal 137, 352-360.

Hanumanthu, S., Butler, J., Chomsky, D., Davis, S. \& Wilson, J.R.(1997). Effect of a heart failure program on hospitalization frequency and exercise tolerance. Circulation 96, 2842-2848. 
Happ, M.B., Naylor, M.D., \& Roe-Prior, P. (1997). Factors contributing to rehospitalization of elderly patients with heart failure. Journal of Cardiovascular Nursing 11(4), 75-84.

Haynes, R.B., Taylor, D.W., \& Sackett, D.L. (Eds.). (1979). Compliance in Health Care. Baltimore, M.D.: The Johns Hopkins University Press.

Hays, R.D., Kravitz, R.L., Mazel, R.M., Sherbourne, C.D., DiMatteo, M.R., Rogers, W.H., Greenfield, S. (1994). The impact of patient adherence on health outcomes for patients with chronic disease in the Medical Outcomes Study. Journal of Behavioral Medicine 17(4), 347-360.

Heidenreich, P.A., Ruggerio, C.M. \& Massie, B.M. (1999). Effect of a home monitoring system on hospitalization and resource use for patients with heart failure. American Heart Journal 138, 633-640.

Hsu, I. (1996). Optimal management of heart failure. Journal of the American Pharmaceutical Association NS36(2), 93-105.

Hulka, B.S., Cassel, J.C., Kupper, L.C., \& Burdette, J.A. (1976). Communication, compliance and concordance between physicians and patients with prescribed medications American Journal of Public Health 66, 847-853.

Jenkins, C.D. (1979). An approach to the diagnosis and treatment of problems of health related behavior. International Journal of Health education 22(supp 2), 1-24.

Karon, B.L. (1995). Concise review for primary-care physicians. Diagnosis and outpatient management of congestive heart failure. Mayo Clinic Proceedings 70 , 1080-1085.

Konstam, M. A., Dracup, K. , Baker, D.W., Bottorff, M.B., Brooks, N.H., Dacey, R.A., Dunbar, S.B., Jackson, A.B., Jessup, M., Johnson, J.C., Jones, R.H., Luchi, R.J., Massie, B.M., Pitt, B., Rose, E.A., Rubin, L.J., Wright, R.F. \& Hadorn, D.C. (1994). Heart failure: Evaluation and care of patients with left ventricular systolic dysfunction. Clinical Practice Guideline No.11. AHCPR Publication No. 94-0612. Rockville, MD: Agency for Health Care Policy and Research, Public Health Service, U.S. Department of Health and Human Services

Krumholz, H.M., Chen, Y.T., Wang, Y., Vaccarino, V., Radford, M.J., \& Horwitz, R.I. (2000). Predictors of readmission among elderly survivors of admission with heart failure. American Heart Journal 139, 72-77. 
Krumholz, H.M., Parent, E.M., Tu, N., Vaccarino, V., Wang, Y., Radford, M.J., \& Hennen, J. (1997). Readmission after hospitalization for congestive heart failure among medicare benificiaries. Archives of Internal Medicine 157, 99-104.

Laing, G. \& Behrendt, D. (1998). A disease management program for home health care patients with congestive heart failure. Home Health Care Management \& Practice10(2), 27-32.

Leventhal, H. (1985). The role of theory in the study of adherence to treatment and doctor-patient interactions. Medical Care 23(5), 556-562.

Levine, T.B., Francis, G.S., Goldsmith, S.R., Simon, A.B., \& Cohn, J.N. (1982). Activity of the sympathetic nervous system and renin-angiotensin system assessed by plasma hormone levels and their relation to hemodynamic abnormalities in congestive heart failure. The American Journal of Cardiology 49, 1659-1666.

Maiman, L.A., Becker, M.H., Kirscht, J.P., Haefner, D.P. \& Drachman, R.H. (1977). Scales for measuring Health Belief Model dimensions: A test of predictive value, internal consistency and relationships among beliefs. Health Education Monographs 5(3), 215-230.

Michalsen, A., Konig, G., \& Thimme, W. (1998). Preventable causative factors leading to hospital admission with decompensated heart failure. Heart 80, 437-441.

McKee, P.A., Castelli, W.P., McNamara, P.M. \& Kannel, W.B. (1971). The natural history of congestive heart failure: The Framingham study. The New England Journal of Medicine 285 (26), 1441-1446.

Monane, M., Bohn, R.L., Gurwitz, J.H., Glynn, R.J., \& Avorn, J. (1994).Noncompliance with congestive heart failure therapy in the elderly. Archives of Internal Medicine 154, 433-437.

Munro, B.H. (1997). Statistical Methods for Health Care Research (3rd ed.).Philadelphia: J.B. Lippincott.

Opasich, C., Febo, O., Riccardi, P.G., Traversi, E., Forni, G., Pinna, G., Pozzoli, M., Riccardi, R., Mortara, A., Sanarico, M., Cobelli, F., \& Tavazzi, L. (1996). Concomitant factors of decompensation in chronic heart failure. The American Journal of Cardiology 78, 354-357.

Packer, M. (1992). Pathophysiology of chronic heart failure. The Lancet 340, 88-92.

Packer, M., Bristow, M.R., Cohn, J.N., Colucci, W.S., Fowler, M.B., Gilbert, E.M., Shusterman, N.H.. for the U.S. Carvedilol Heart Failure Study Group. (1996). The effect 
of carvedilol on morbidity and mortality in patients with chronic heart failure. The New England Journal of Medicine 334(21), 1349-1355.

Pearson, T.A., \& Peters, T.D. (1997). The treatment gap in coronary artery disease and heart failure: Community standards and the post-discharge patient. American Journal of Cardiology $80(8 \mathrm{~B}), 45 \mathrm{H}-52 \mathrm{H}$.

Pepper, G.S. \& Lee, R.W. (1999). Sympathetic activation in heart failure and its treatment with Beta-blockade. Archives of Internal Medicine 159, 225-234.

Pitt, B. Segal, R., Martinez, F.A., Meurers, G., Cowley, A.J., Thomas, I., Deedwania, P.C.k, Ney, D.E., Snavely, D.B., Chang, P.I. on behalf of Elite Study Investigators. (1997). Randomised trial of losartan vs. captopril in patients over 65 with heart failure (Evaluation of losartan in the elderly study, ELITE). The Lancet 349, 747-752.

Polit, d.F., \& Hungler, B.P. (1991). Nursing Research. Principles and Methods (4th ed.). Philadelphia: J.B. Lippincott.

Redeker, N.S. (1988). Health beliefs and adherence in chronic illness. Image: Journal of Nursing Scholarship 20(1), 31-35.

Rich, M.W., Beckham, V., Wittenberg, C., Leven, C.L., Freedland, K.E., \& Carney, R.M. (1995). A multidisciplinary intervention to prevent the readmission of elderly patients with congestive heart failure. The New England Journal of Medicine 333 (18), 1190-1195.

Rich, M.W., Gray, D.B., Beckham, V., Wittenberg, C., Luther., P. (1996). Effect of a multidisciplinary intervention on medication compliance in elderly patients with congestive heart failure. American Journal of Medicine 101, 270-276.

Romm, F.J., Hulka, B.S., \& Mayo, F. (1976). Correlates of outcomes in patients with congestive heart failure. Medical Care 14(9), 765-776.

Rosenstock, I.M. (1974). Historical origins of the health belief model. Health Education Monographs 2(4), 329-335.

Sackett, D.L., \& Haynes, R.B. (Eds.). (1976). Compliance with Therapeutic Regimens. Baltimore, MD: Johns Hopkins University Press.

Senni, M., Tribouilloy, C.M., Rodeheffer, R.J., Jacobsen, S.J., Evans, J.M., Bailey, K.R., \& Redfield, M.M. (1999). Congestive heart failure in the community. Trends in incidence and survival in a 10 year period. Archives of Internal Medicine 159, 29-34. 
Shah, N.B., Der, E., Ruggerio, C., Heidenreich, P.A. \& Massie, B.M. (1998). Prevention of hospitalizations for heart failure with an interactive home monitoring program. American Heart Journal 135, 373-378. Inc.

SPSS version 9.0 for Windows [Computer software]. (2000). Chicago, IL: SPSS,

Struthers, A.D., Anderson, G., Donnan, P.T. and MacDonald, T. (2000). Social deprivation increases cardiac hospitalisations in chronic heart failure independent of disease severity and diuretic non-adherence. Heart 83, 12-16.

The Digitalis Investigation Group. (1997). The effect of digoxin on mortality and morbidity in patients with heart failure. The New England Journal of Medicine 336(8), 525-533.

The SOLVD (Studies of Left Ventricular Dysfunction)Investigators (1991). Effect of enalapril on survival in patients with reduced left ventricular ejection fractions and congestive heart failure. The New England Journal of Medicine 325(5), 293-302.

Vinson, J.M., Rich, M.W., Sperry, J.C., Shah, A.S., \& McNamarra, T. (1990). Early readmission of elderly patients with congestive heart failure. Journal of the American Geriatrics Society $38,1290-1295$.

West, J.A., Miller, N.H., Parker, K.M., Senneca, D., Ghandour, G., Clark, M., Greenwald, G., Heller, R.S., Fowler, M.B., \& DeBusk, R.F. (1997). A comprehensive management system for heart failure improves clinical outcomes and reduces medical resource utilization. American Journal of Cardiology 79, 58-63. 
APPENDIX A-Instruments 
Instructions: These are statements about your sex, race, age and symptoms of heart failure . Please read the following three statements and circle one number for the choice after each statement that best describes you. Following the fourth statement, please write your age in years.
a. I am a: 1. Male
2. Female

b. My race is: 1. Hispanic 2. White Non-Hispanic 3.Black Non-Hispanic 4. American Indian 5. Asian 6. Other (Specify)

c. The best description of my functional capacity (my ability to do physical activity) is:

\section{(CIRCLE ONE NUMBER ONLY BELOW)}

1. I have been told I have heart failure but it does not limit my physical activity.

2. I am comfortable at rest but walking 100 feet on level ground makes me feel: tired, short of breath, like my heart beats too fast, like my heart beats irregularly, pressure in my chest, pain in my chest, tightness in my chest.

3. I am comfortable at rest but getting dressed makes me feel: tired, short of breath, like my heart beats too fast, like my heart beats irregularly, pressure in my chest, pain in my chest, tightness in my chest.

4. Any physical activity makes me feel: tired, short of breath, like my heart beats too fast, like my heart beats irregularly, pressure in my chest, pain in my chest, tightness in my chest

d. I am years old. 
ID\#:

Date:

Data Collected by:

\section{BELIEFS ABOUT MEDICATIONS}

INSTRUCTIONS: These are questions about the benefits of and barriers to taking your medicines, especially your diuretics, or water pills. Please read each statement below and circle the number that best describes how much you agree or disagree with the statement.

$\begin{array}{ll}1= & \text { Strongly Disagree } \\ 2= & \text { Disagree } \\ 3= & \text { Undecided } \\ 4= & \text { Agree } \\ 5= & \text { Strongly Agree }\end{array}$

\begin{tabular}{|l|c|c|c|c|c||}
\hline & SD & D & U & A & SA \\
\hline $\begin{array}{l}\text { 1. When I take my water pills, I do not worry as much about my heart } \\
\text { disease. }\end{array}$ & 1 & 2 & 3 & 4 & 5 \\
\hline 2. If I take my water pills, I will lower my chance of being in the hospital. & 1 & 2 & 3 & 4 & 5 \\
\hline 3. $\quad$ Taking water pills is hard to remember. & 1 & 2 & 3 & 4 & 5 \\
\hline 4. Taking water pills is unpleasant. & 1 & 2 & 3 & 4 & 5 \\
\hline 5. I have to take too many water pills each day. & 1 & 2 & 3 & 4 & 5 \\
\hline 6. Taking water pills makes it hard to go away from home. & 1 & 2 & 3 & 4 & 5 \\
\hline 7. Taking my water pills lessens my swelling. & 1 & 2 & 3 & 4 & 5 \\
\hline 8. I forget to take my water pills. & 1 & 2 & 3 & 4 & 5 \\
\hline 9. Taking water pills makes me worry about my heart disease. & 1 & 2 & 3 & 4 & 5 \\
\hline 10. Taking my water pills helps me breathe better. & 1 & 2 & 3 & 4 & 5 \\
\hline 11. Taking my medicine improves my quality of life. & 1 & 2 & 3 & 4 & 5 \\
\hline 12. Taking water pills makes me wake up at night to go to the bathroom. & 1 & 2 & 3 & 4 & 5 \\
\hline
\end{tabular}


ID\#:

Date:

Data Collected by:

\section{BELIEFS ABOUT DIET}

INSTRUCTIONS: These are questions about the benefits of and barriers to following a low sodium (low salt) diet. Please read each statement below and circle the number that best describes how much you agree or disagree with the statement.

$$
\begin{aligned}
& 1=\text { Strongly Disagree } \\
& 2=\text { Disagree } \\
& 3=\text { Undecided } \\
& 4=\text { Agree } \\
& 5=\text { Strongly Agree }
\end{aligned}
$$

\begin{tabular}{||l|c|c|c|c|c||}
\hline & SD & D & U & A & SA \\
\hline 1. $\quad$ Eating a low salt diet will keep me healthy. & 1 & 2 & 3 & 4 & 5 \\
\hline 2. Salty food is not good for me. & 1 & 2 & 3 & 4 & 5 \\
\hline 3. $\quad$ Eating a low salt diet will keep my heart healthy. & 1 & 2 & 3 & 4 & 5 \\
\hline 4. $\quad$ Eating a low salt diet will keep my swelling down. & 1 & 2 & 3 & 4 & 5 \\
\hline 5. $\quad$ Eating a low salt diet will keep fluid from building up in my body. & 1 & 2 & 3 & 4 & 5 \\
\hline 6. I cannot go out to many places to eat because of the low salt diet. & 1 & 2 & 3 & 4 & 5 \\
\hline 7. Food does not taste good on the low salt diet. & 1 & 2 & 3 & 4 & 5 \\
\hline 8. Following a low salt diet costs too much money. & 1 & 2 & 3 & 4 & 5 \\
\hline 9. Following a low salt diet takes too much time. & 1 & 2 & 3 & 4 & 5 \\
\hline 10. Following a low salt diet is too hard to understand. & 1 & 2 & 3 & 4 & 5 \\
\hline 11. When I follow my low salt diet, I feel better. & 1 & 2 & 3 & 4 & 5 \\
\hline 12. Eating a low salt diet will help me breathe easier. & 1 & 2 & 3 & 4 & 5 \\
\hline
\end{tabular}


APPENDIX B-Consent 
FLORIDA INTERNATIONAL UNIVERSITY

School of Nursing
OCT 201999

BGM

"A descriptive correlation of medication and dietary compliance beliefs with functional limitations in heart failure patients"

\section{CONSENT FORM}

I am a graduate student from Florida International University, School of Nursing inviting you to participate in a research study to describe heart failure patients' beliefs about taking their medicines, following their diets and how these beliefs may relate to ability to do physical activity. This study is being conducted as a partial requirement toward completion of a master's degree in Nursing.

You are being invited to participate as a person managing your heart failure treatment here in an outpatient clinic program. Information obtained from these questionnaires will be kept confidential and all data will be handled by the pricipipal investigator, major professor and statistician.Each questionnaire is completely anonymous and results will be reported in terms of group data. No information will be released or published in which your name or identifying information will be given.

Attached you will find three short questionnaires with instructions. If you choose to participate, please follow the instructions to indicate your sex, race, age, ability to do physical activity, beliefs about taking prescribed medicine for your heart failure and beliefs about following your prescribed diet. About 15-20 minutes is needed to answer all the questions. When you're finished, please return the questionnaire package to the clinic nurse or to me, the principal investigator.

There are no known risks or benefits involved in participating in the study. There is no monetary compensation or fees to pay. Your participation is voluntary and does not affect your treatment at the heart failure clinic in any way. You may withdraw your consent and discontinue your participation in the study at any time with no megative consequences.

If at any time you have a question regarding this study, need further information, or want a copy of the study summary, please contact Dorothy B. Diener, RN at (561) 487-8322 and /or Dr. Luz Porter at Florida International University, School of Nursing (305) 919-5915. If you have any questions or concerns related to your rights as a research participant, you may contact the IRB Coordinator at Broward General Medical Center, 1600 S.Andrews Ave., Ft.Lauderdale (954) 355-5560.

The research procedure described here has been fully explained to me, I have been offered a copy of this consent form and I choose to participate by completing the survey.

Participant's signature

Principal Investigator's signature
Date

Date 
APPENDIX C-IRB/URC Application 


\section{APPLICATION FOR APPROVAL OF RESEARCH INVOLVING HUMAN SUBJECTS}

1. PROJECT TITLE: A descriptive correlation of medication and dietary compliance beliefs with functional limitations in heart failure patients.

2. PRINCIPAL INVESTIGATOR: Dorothy B. Diener RN, BSN SS\#: 113-54-5772 Address: 4613 Bison St. Boca Raton, FL 33428 Phone: Home (561) 487-8322

Position: [ ] Faculty [ X] Graduate student [ ] Undergraduate student (Voice Mail) [ ] Other

3. FACULTY SUPERVISOR (if PI is a student): Dr. Luz S. Porter, $\mathrm{PhD}, \mathrm{ARNP}, \mathrm{FNP}$

4. STATUS OF PROJECT REVIEW:

[ X] New project [ ] Revision of previously approved project

[ ] Continuation of approved project

5. BRIEF DESCRIPTION OF SUBJECTS

Number of subjects: 61

Check all of the following categories that describe your research subjects:

[X] Males

[X] Females

[ ] Minors (under 18 years old)

[ ] Students (Please specify):

[ ] Persons With Physical Disablities (Please specify):

[ ] Persons With Mental/Psychological Disabilities (Please specify) :

[X] Persons With Physical or Mental Health Problems : Subjects will have a medical diagnosis of heart failure

[ ] Persons With No Known Disabilities and No known health Problems

[ ] Prisoners

[ ] Pregnant women, fetuses, fetal material or placenta (Please specify):

[X] Persons in some type of program: Outpatients of a S. Florida specialized heart failure clinic program

[X] Other Pertinent Information : Subjects will be alert, oriented English speakers.

6. TYPE OF REVIEW REQUESTED

[ ] Exempt: Category\#(s)

[X] Expedited Review: Category \# 9

[ ] Full URC Review 


\section{RESEARCH OBJECTIVES}

a. To determine heart failure clinic patients' beliefs about medication and dietary compliance (Bennett, Milgrom, Champion \& Huster, 1997).

b. To determine if patient-reported functional limitations secondary to heart failure relate to patient beliefs about medication and dietary compliance.

\section{SUBJECT RECRUITMENT}

Bennett et al. (1997) recruited 61 alert, oriented, English speaking patients with a medical diagnosis of heart failure from a hospital's specialized outpatient clinic to participate in the development of an instrument designed to measure beliefs about compliance with medication and diet. I plan to obtain a convenience sample utilizing the inclusion criteria of Bennett et al. (1997) by recruiting 61 alert, oriented English speaking male and female patients, 18 years of age or older, diagnosed with heart failure from a: South Florida outpatient heart failure clinic. Informed consent will be obtained prior to inclusion in the study.

\section{BENEFITS}

a. No direct benefits will be promised to secure study participation. No direct benefits will be received by those who choose to participate. Patients' routine heart failure management will be unaffected by study participation.

b. The anticipated benefits of this research to society stems from its attempt to both describe and explore what may potentially relate to compliance with treatment in the practical management of a costly chronic illness. Assessing and utilizing heart failure patients' beliefs about compliance with therapeutic regimen may allow practitioners to better individualize educational interventions that ultimately increase compliance with medication and diet. Increased compliance with therapeutic regimen may maximize the individual's health potential by both promoting better health and preventing acute decompensation and rehospitalization in the heart failure patient.

\section{INFORMED CONSENT}

A document detailing the nature and purpose of the study, its lack of direct risk and benefit, the nature of participation and participant selection, a pledge of confidentiality and contact information for direct access to the principal investigator will serve to inform potential participants. Informed consent will be obtained from each participant by the principal investigator. 


\section{CONFIDENTIALITY OF DATA}

All participants will be assured that information obtained in the course of this study will be kept strictly confidential and all data received by the clinic practitioner and/or principal investigator will only be handled by the principal investigator, major professor and statistician. Participants will be assured of questionnaire anomymity and will not be asked to indicate their names on any portion of the questionaire packet. Participants will be assured that all results will be reported as group data. No information will be released or published in which individual participant's names or identifying data will be disclosed. Completed questionnaires returned to clinic practitioners will be retained on site in a locked box for weekly collection by the principal investigator. A five to ten week time frame is estimated to obtain 61 study participants. All questionnaires will be secured by the principal investigator and stored in a locked cabinet for a minimum of three years in the investigator's home.

\section{METHOD AND PROCEDURE}

Approval of this research protocol and permission to conduct the study will be obtained from Florida International University and the research review committee of the agency from which participants will be recruited.

Informed heart failure clinic patients who indicate their consent to participate will be instructed to complete:

a. a demographic questionnaire

b. the Beliefs about Medication Compliance Scale (BMCS)

c. the Beliefs about Dietary Compliance Scale (BDCS)

Each questionnaire contains instructions to participants for its completion. Questionnaire completion should take approximately 15-20 minutes.

\section{STIMULUS MATERIALS}

\section{Instruments:}

a. Demographics.

Participants will indicate their race, sex, age and New York Heart Association (NYHA) class I-IV operationalized to indicate functional capacity. Content validity of operationalized NYHA class levels is supported by expert panel review.

b.Beliefs about Medication Compliance Scale (BMCS)

Beliefs about Dietary Compliance Scale (BDCS) 
Participants will use a five point scale (1=strongly disagree, to $5=$ strongly agree)to indicate response to items designed to measure perceived benefits and perceived barriers to compliance with both medication and dietary regimen central to heart failure management (Bennett et al., 1997).

\section{STIMULUS MATERIALS}

Instruments continued:

A content validity index of 0.81 was reported and construct validity of both the BMCS and BDCS was supported by factor analysis (Bennett et al., 1997). "Internal consistency reliabilities of the perceived benefits and barriers subscales of the BMCS and BDCS were computed using Cronbach's alpha statistic" with reported values ranging from 0.68 to 0.91 (Bennett et al., 1997, p.277).

\section{RISKS TO SUBJECTS}

Participants will not be subject to any physical contact nor experimental manipulation in this study. Neither will participants be subject to any social repercussions, economic demands, psychological risks or legal liabilities in this study. The letter of introduction will clearly inform potential subjects that study participation is wholly voluntary. 
APPENDIX D-Request to Use Instruments 
Dr.Susan J. Bernett, DNS

Indian University

School of Nursing

1111 Middle Dr.

Indiesupolis, IN 46202

Dear Dr. Bennett:

Please allow this letter to serve as my introduction. I am a registered nurse currently pursuing my master's degree in nursing science at Florida International University in North Miami. I reside in South Florida and work as a full time staff nurse (CCU/CVICU) at a large, urban, tax assisted teaching hospital here. I am writing to express my great interest in the instrument you developed to measure heart failure patients' compliance beliefs as published in Heart \& Lung. July/August, 1997.

With your permission, I would like to replicate the use of both your Beliefs about Medication Compliance and Beliefs about Dietary Compliance Scales as they appear in Heart \& Lung, in my muster's thesis this year. I am currently completing my research proposal.

I plan to distribute the scales in my hospital district's outpatient heart failure clinic. While witing to see the advanced practice nurses who provide care in the clinic, the patient's will be offered the opportunity to participate in my study and indicate their beliefs about medication and diet compliance by completing your scales. Our population here is representative of multiple races and cultures lending diversity to the study.

In addition to replicating the use of your scales to generate descriptive data, I plan to explore the relationship, if any, between a heart failure patient's scale scores and their functional capacity by NYHA class. I seek to answer the following question: Is there a relationship between scale scores meanuring beliefs about treatment compliance and functional limitations in people with heart failure?

I appreciate your consideration in this matter and shall look forward to your reply. My email and street addresses as well as my telephone number which includes voice messaging are enclosed for your convenience. Thank you and best regards.

Sincerely,

Dorothy Diener, $\mathbf{R N}$ 
APPENDIX E-Letters in: Approval to Use Instruments, Scoring Instructions, IRB Approval, URC Approval 
Subj: Scales

Date: $\quad 99-02-04$ 13:50:39 EST

From: sbennet@iupui.edu (Bennett, Susan J)

To: mtarkus@aol.com (mtarkus@aol.com)

Dorothy, I received your request for the Belief Scales and am sending you the information by U.S. mail today. Susan Bennett

\author{
Susan J. Bennett, DNS, RN \\ Associate Professor \\ Indiana University School of Nursing \\ 1111 Middle Drive \\ Indianapolis, IN 46202 \\ (317) $274-4432$ (telephone) \\ (317) 278-1856 (Fax) \\ sbennet@iupui.edu <mailto:sbennet@iupui.edu> (e-mail)
}

Return-Path: <sbennet@iupui.edu>

Received: from Hy-yc02 mx.aol.com (nly-yc02.mail.aol.com [172.18.149.34]) by air-yc02.mail.aol.com (V56.24) with SMTP; Thu, 04 Feb 1999 13:50:39 -0500

Received: from iris.iupui.edu (Iris.iupui.edu [134.68.220.32]) by ny-yc02.mx.aol.com (vx) with SMTP; Thu, 04 Feb 1999

13:50:11 -0500

Received: from lynx. uits.iupui.edu (lynx.uits.iupui.edu [134.68.220.22])

by iris.iupui.edu (8.9.1a/8.9.1/1.18IUPUIPO) with ESMTP id NAA20783

for<mtarkus@aol.com>; Thu, 4 Feb 1999 13:50:10-0500 (EST)

Received: by lynx.uits.iupui.edu with Internet Mail Service (5.5.2448.0)

id <1DTDBSAV>; Thu, 4 Feb 1999 13:50:10-0500

Message-1D: <CD5DFED91D8ED21198C30008C74C7A08B6741D@jaguar.uits.jupui.edu>

From: "Bennett, Susan J" <sbennet@iupui.edu>

To: "mtarkus@aol.com" <mtarkus@aol.com>

Subject: Scales

Date: Thu, 4 Feb 1999 13:50:09 -0500

MIME-Version: 1.0

X-Mailer: Internet Mail Senice (5.5.2448.0)

Content-Type: text/plain 
SCHOOL OF NURSING

February 4, 1999

Dorothy Diener, RN

4613 Bison Street

Boca Raton, FL 33428

Dear Ms. Diener:

You have my permission to use the Beliefs about Medication Compliance Scale and the Beliefs about Dietary Compliance Scales for your master's degree research project. I have enclosed current copies of the Scales as well as scoring instructions. Additionally, we have developed a third scale entitled Beliefs about Self-Monitoring. I have enclosed a copy of this scale, too. The self-monitoring scale is being testing for reliability this semester by a graduate nursing student in Indiana. You are welcome to include this scale, too. If you do, please send me information regarding the reliability of the scale in your sample.

Best wishes with your research project. Feel free to contact me if you need additional information.

Sincerely,

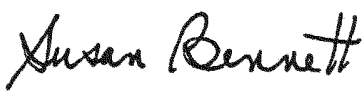

Susan J. Bennett, DNS, RN

Associate Professor

DEPARTMENT OP ADUT HRAITH

1111 Middle Drive Indianapolis, Indiana $46202-5107$

$317-274-0024$ Fax: $317-278-1856$ 
Eealth Belier Scales and Scoring Instructions

developed by

Susan Denuett, DNS, RN

Ledley Milgrow, MSN, RN

Indiana Univerity Schoel of Nursine

For additional information, please contact Susan J. Bennett, DNS, RN, Associate Professor, Indi Uaiversity School of Nursing, 1111 Middle Dr., Indianapolic, IN 16202.

Telephone - (317) 274-4332; Fax - (317) 278-1856; E-mill - sbennet@iupui.edu

Copyright O August 1998 Susan J. Bennett, DNS, RN 


\section{Instructions for Scoring the Beliefs About Compliance Scales}

Susan J. Bennett, DNS, RN.

Each Belief Scale has two scores: A Benefits Score and a Barriers Score. Scores are obtained as follows:

1. Score all individual items as:

$$
\begin{aligned}
& 1=\text { "Strongly Disagree" } \\
& 2=\text { "Disagree" } \\
& 3=\text { "Undecided" } \\
& 4=\text { "Agree" } \\
& 5=\text { "Strongly Agree" }
\end{aligned}
$$

2. Reverse code item 9 on the Beliefs About Medications Scale.

3. Reverse code item 2 on the Beliefs About Diet Scale.

4. Compute a Benefits Score and a Barriers Score for each instrument by summing individual items of each subscale. The subscales for the Medication and Diet Scales are identified in the article by Bennett, Milgrom, Champion, and Huster, Heart and Lung, 1997, Volume 26, pp. 273-9. The subscales for the Self-monitoring Scale are enclosed. 
Benefits and Barriers Coding Sheet .

\begin{tabular}{|c|c|}
\hline Benefit & 1. When I take my water pills, I do not worry as much about my heart disease. \\
\hline Benefit & 2. If I take my water pills, I will lower my chance of being in the hospital. \\
\hline Barrier & 3. Taking water pills is hand to remember. \\
\hline Barrier & 4. Taking water pills is unpleasant. \\
\hline Barrier & 5. I have to take too many water pills each day. \\
\hline Barrier & 6. Taking water pills makes it hard to go away from bome. \\
\hline Benefit & 7. Taking my water pills lessens my swelling. \\
\hline Burrier & 8. If forget to take my water pills. \\
\hline Benent* & 9. Taking water pills makes me worry about my heart disease. \\
\hline Benent & 10. Taking my water pills helps me breathe better. \\
\hline Benerit & 11. Taking my medicine improves my quality of life. \\
\hline Barrier & 12. Taking water pills makes me wake up at night to $g$ to the bathroom. \\
\hline
\end{tabular}

Recode 9 when scoring

Copynght 1998 Susan J. Bennet, DNS. RN 


\section{Benefits and Barriers Coding Sheet}

\begin{tabular}{|c|c|}
\hline Bement & 1. Eating a low salt diet will koep me heal hy. \\
\hline Beaefit & 2. Salty food is not good for me. \\
\hline Beaent & 3. Eating a low salt diet will keep my beart healthy. \\
\hline Benefit & 4. Eating a low salt diex will keep my swelling down. \\
\hline Benefit & 3. Eating a low salt diet will keep fluid from building up in my body. \\
\hline Barrier & 6. I cannot go out to muny places to cat because of the low salt diet. \\
\hline Barrier & 7. Food does not taste good on the low salt diet. \\
\hline Barrier & 8. Following a low salt diet costs woo much money. \\
\hline Barrier & 9. Following a low salt diet taken too much time. \\
\hline Barrter & 10. Following a low alt diet is too hard to understand. \\
\hline Bemefit & 11. When I follow my low salt diet, I feel better. \\
\hline Benefit & 12. Eating a low salt diet will help me breathe easier. \\
\hline
\end{tabular}

-Recode when scoring 


\section{AFFIRMATION OF COMPLIANCE AND ACCEPTANCE OF RESPONSIBIITY}

I agree to follow the procedures outlined in this summary description and any attachments. I understand that no contact may be initiated with subjects until I have received approval of these procedures from the URC and have complied with any modifications required in connection with that approval. I understand that additions to or changes in the procedures involving human subjects can only be made after approval of the URC. I understand that I must promptly report to the URC any problems with the rights or welfare of the human subjects. I understand and will follow Florida International University's policies concerning research with human subjects. I will do everything in my power to protect the rights and welfare of human subjects in my research project.

A descriptive correlation of medication and dietary compliance beliefs with functional limitations in heart failure patients. (print title of project here)

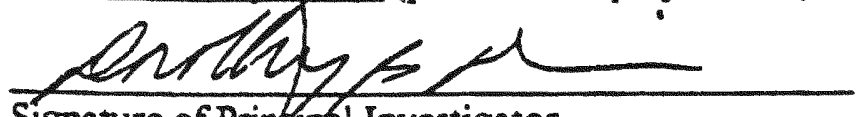

Signature of Prineipal Investigator

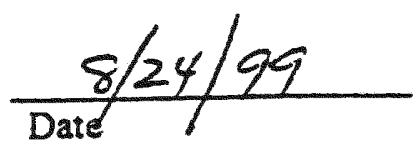

Dorothy B. Diener RN, BSN

Printed name of Principal Investigator

If the PI is a student, the faculty supervisor must sign below.

I have read this application and assume responsibility for its accuracy and for supervision of the propgsed research project.

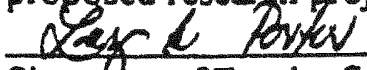

Signalure of Fagulty Supervisor

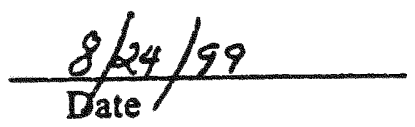

Printed name of Faculty Supervisor

ACTION RECOMMENDED BY URC * For URC use only** Date:Sept5, 155 [ [4 Approved [ ] Changes/Clarifications Requested [ ] Require Full Board

Doughs A. COFËD, RO,, PAD, AROA

Dough ACOFEN

Printed name of URC Chairperson

Date: [ ] Approved [ ] Changes/Clarifications Requested

] Require Full Board Review

Signature of URC Chairperson

Date: [ ] Approved [ ] Changes/Clarifications Requested [ ] Require Full Board Review

Signature of URC Chairperson 
Date: September 10, 1999

To: $\quad$ Dorothy B. Diener, RN, BSN, Master's Student

Dr. Luz Porter, Professor and Chair: Thesis/Research Project

From:

Douglas A. Coffin, $K$ N, C., Ph.D. ATNP SON URC Representative

Re: $\quad$ Application for approval of research involving human subjects titled: "A descriptive correlation of medication and dietary compliance beliefs with : functional limitations in heart failure patients."

\section{Cc: URC Chairperson}

Your application has been approved for exempt and/or expedited status. Please be aware that you have agreed to follow the procedures outlined in your summary description and any attachments. You may not contact subjects until you have received this written notification of approval. You understand that any additions to or changes in the procedures involving human subjects can only be made after approval of the URC or its departmental representatives. You understand that you must promptly report to the URC any problems with the rights or welfare of the human subjects. You understand and will follow Florida International University's polices and procedures concerning research with human subjects. You will do everything with your power to protect the rights and welfare of human subjects in your research project.

Good luck on your project/research and congratulations. 


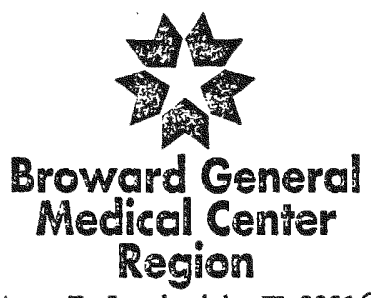

December 15, 19991600 S. Andrews Ave., Ft. Lauderdale, FL 33316 • (954) 355-4400

Dorothy B. Diener, RN, BSN

4613 Bison Street

Boca Raton, FL 33428

SUBJECT: A descriptive correlation of medication and dietary compliance beliefs with functional limitations in heart failure patients. Follow up October 20, 1999 meeting. Correction of date

Dear Mrs. Diener:

At its meeting on October 20, 1999, the Institutional Review Board (IRB) of Broward General Medical Center reviewed the protocol and the letter of introduction related to the above named research proposal. After discussion of this matter, the IRB reviewed and approved the proposal. The informed consent was approved contingent upon the following revision.

1. Please delete this paragraph "I am hopeful that information obtained from this study will assist nurse educators to better teach patients to manage their heart failure. Thank you for you interest and consideration."

2. Revised the last sentence to indicate that the researcher has explained the research procedure, a copy of the informed consent has been offered, and that the participant agrees to participate.

This study has been approved for one year, and the next progress report is due before October 20 , 2000.

In addition you are required to:

- Promptly report to the IRB any changes in research activity including protocol closure,

- Ensure that changes in the approved research during the period for IRB approval has already been given may not be initiated without $\mathbb{R B}$ review and approval unless where necessary to eliminate apparent hazard to the human subjects,

- Prompt report unanticipated problems involving risk to human subjects or others.

The IRB of Broward General Medical Center has the authority to have a third party observe the consent process and the research.

This IRB is in conformance with the requirements in Title 21, Part 56, Sub-Part A-D, of the Code of Federal Regulations published April 1, 1996.

Sincerely,

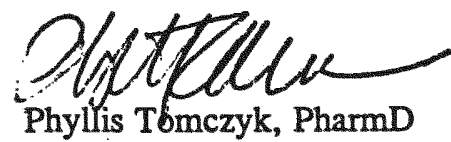

Coordinator - T3451

North Broward Hospital District

H:URBLDIENER-DEC1999

A facility of the North Broward Hospital District. The Nortb Broward Hospital District is affliated with the University of Florida and Nova Soutbeastern Colleges of Medicine and is an equal opportuntiy employer and affirmative action procurer of goods and services. 